\title{
Biodefense Implications of New-World Hantaviruses
}

\author{
Michael Hilary D'Souza ${ }^{1 \dagger}$ and Trushar R. Patel ${ }^{1,2,3 * \dagger}$ \\ 1 Department of Chemistry and Biochemistry, Alberta RNA Research and Training Institute, University of Lethbridge, \\ Lethbridge, AB, Canada, ${ }^{2}$ Department of Microbiology, Immunology and Infectious Disease, Cumming School of Medicine, \\ University of Calgary, Calgary, AB, Canada, ${ }^{3} \mathrm{Li}$ Ka Shing Institute of Virology and Discovery Lab, University of Alberta, \\ Edmonton, $A B$, Canada
}

OPEN ACCESS

Edited by:

Stephen Allen Morse

Centers for Disease Control and Prevention (CDC), United States

Reviewed by:

Segaran P. Pillai,

United States Department of Homeland Security, United States Wei Zou,

University of Michigan, United States

${ }^{*}$ Correspondence:

Trushar R. Patel trushar.pate/@uleth.ca

tORCID:

Michael Hilary D'Souza orcid.org/0000-0001-8709-4019

Trushar R. Patel

orcid.org/0000-0003-0627-2923

Specialty section:

This article was submitted to

Biosafety and Biosecurity,

a section of the journal

Frontiers in Bioengineering and

Biotechnology

Received: 26 May 2020

Accepted: 17 July 2020

Published: 07 August 2020

Citation:

D'Souza MH and Patel TR (2020)

Biodefense Implications

of New-World Hantaviruses.

Front. Bioeng. Biotechnol. 8:925.

doi: 10.3389/fbioe.2020.00925
Hantaviruses, part of the Bunyaviridae family, are a genus of negative-sense, single-stranded RNA viruses that cause two major diseases: New-World Hantavirus Cardiopulmonary Syndrome and Old-World Hemorrhagic Fever with Renal Syndrome. Hantaviruses generally are found worldwide with each disease corresponding to their respective hemispheres. New-World Hantaviruses spread by specific rodent-host reservoirs and are categorized as emerging viruses that pose a threat to global health and security due to their high mortality rate and ease of transmission. Incidentally, reports of Hantavirus categorization as a bioweapon are often contradicted as both US National Institute of Allergy and Infectious Diseases and the Centers for Disease Control and Prevention refer to them as Category $\mathrm{A}$ and $\mathrm{C}$ bioagents respectively, each retaining qualitative levels of importance and severity. Concerns of Hantavirus being engineered into a novel bioagent has been thwarted by Hantaviruses being difficult to culture, isolate, and purify limiting its ability to be weaponized. However, the natural properties of Hantaviruses pose a threat that can be exploited by conventional and unconventional forces. This review seeks to clarify the categorization of Hantaviruses as a bioweapon, whilst defining the practicality of employing New-World Hantaviruses and their effect on armies, infrastructure, and civilian targets.

Keywords: hantavirus, Sin Nombre Virus, Andes Virus, biodefense, bioterrorism, viral pandemic, hantavirus cardiopulmonary syndrome, transmission

\section{INTRODUCTION}

Hantaviruses are emerging zoonotic viruses that are responsible for two human diseases: Hantavirus Cardiopulmonary Syndrome (HCPS) associated with New-World Hantaviruses found in the western hemisphere; and Hemorrhagic Fever with Renal Syndrome (HFRS) associated with Old-World Hantaviruses in the eastern hemisphere (Mittler et al., 2019). Collectively, 150,000 200,000 cases of hantavirus disease are reported annually with the majority of HFRS cases occurring in Asia, specifically in the People's Republic of China which constitutes upwards of $90 \%$ of cases (Schmaljohn, 2009; Iannetta et al., 2019; Liu et al., 2019). HCPS, comparatively, presents a stark minority in annual cases, roughly 300, with the majority of cases being in South America and primarily Brazil (Watson et al., 2014; Duehr et al., 2020). The annual average cases of New-World HCPS-causing hantaviruses in the western hemisphere are summarized in Figure 1. Both HFRS and HCPS exhibit drastically different mortality rates, with the former causing upwards of $12 \%$ while the latter inflicting upwards of $35-50 \%$ mortality on infected persons (Jonsson et al., 2010; 

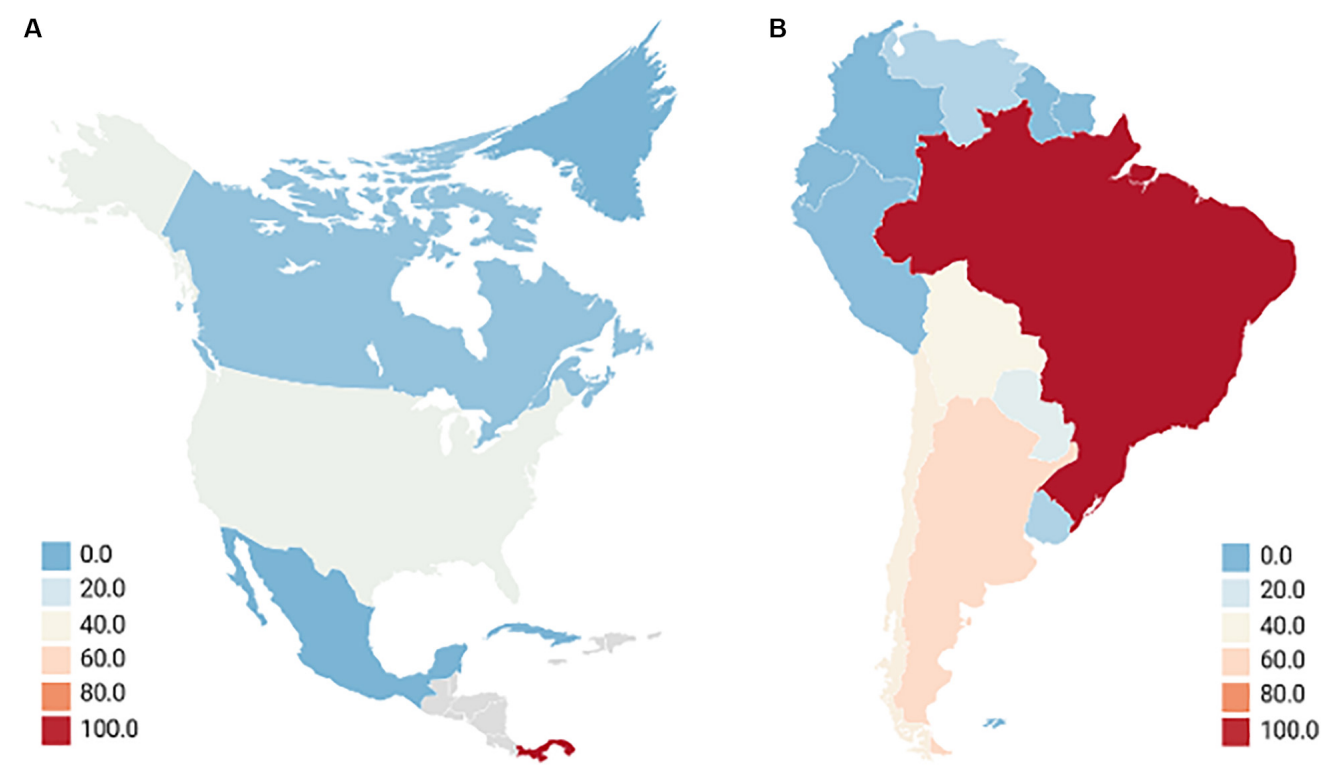

FIGURE 1 | Annual average cases of new-world hantaviruses in the western hemisphere. North America (A) although Mexico has reported there being no HCPS cases, seroprevalence of hantaviruses exists in $10.15 \%$ of rodents, much of which occurs in Mexican states that border the United States where 299 cases of HCPS were reported between 1993 and 2017. Seropositive humans were identified, and the lack of reporting is attributed to the febrile disease being misconstrued with other illnesses (Vigueras-Galvan et al., 2019). This is very similar to other Central Latin American nations which have very limited reporting or insufficient data but show seroprevalence of hantavirus in rodents, up to 20.8\% in Honduras as an example (Knust and Rollin, 2013; Rovida et al., 2013; Montoya-Ruiz et al., 2014; Drebot et al., 2015). Gray locations indicate countries with no reporting of hantavirus. South America (B) most cases occurred in rural or forested environments with farming being a major concern. Reporting is an issue as the actual annual cases for Brazil, Columbia, and Venezuela are considered to be significantly higher (Figueiredo et al., 2014; Montoya-Ruiz et al., 2014; Goeijenbier et al., 2015; Riquelme et al., 2015; Jiang et al., 2017; Matheus et al., 2017; Fonseca et al., 2018; Alonso et al., 2019; Escalera-Antezana et al., 2020). Averages of HCPS-causing hantavirus cases taken from studies carried out between 2000 and 2019.

Llah et al., 2018). Due to hantaviruses being emerging pathogens with HCPS-causing infections retaining a high mortality rate, there remains a possible risk of hantaviruses being engineered into novel bioweapons (Meyer and Morse, 2008; Kruger et al., 2011; Williams and Sizemore, 2020).

Biological systems that can potentially be used as weapons have been divided into three groups designated Category A, B, and C (Table 1) (Christian, 2013). Category A agents are described as organisms or toxins that pose a national security risk because they can be easily transmitted or disseminated, can result in high mortality with a major public health impact, can cause public panic and social disruption, and require special action to ensure public health preparedness (Christian, 2013). Category A agents include Bacillus anthracis, Clostridium botulism neurotoxin, and viral hemorrhagic fever viruses such as Ebola and Marburg. Category A agents are especially important because of their high mortality rate and rapid disease progression. For example, the spores of $B$. anthracis are highly resistant to adverse environmental conditions such as heat, cold, humidity, and radiation (Doganay and Demiraslan, 2015). These spores are easily produced in laboratories, dried, and refined as a powder that can be released as an aerosol, which if inhaled, can result in inhalation anthrax, meningitis, and bacteremia. If untreated, the disease is highly fatal (Miroslav, 2020).

Category $\mathrm{B}$ agents are the second-highest priority agents and typically include agents that are responsible for moderate morbidity and low mortality rates, and are moderately dispersible
(Christian, 2013). They tend to include food safety threats and diseases from toxins like the Ricin toxin from Castor beans (Ricinus communis) that can be employed in local attacks and assassinations that have a low death rate compared to Category A agents but can still inflict significant damage to political and social systems (Bhalla and Warheit, 2004). This contrasts with the third-highest priority, Category $\mathrm{C}$ Pathogens which can include emerging pathogens that could be engineered for mass dissemination through their: availability, ease of production and dissemination; and their potential for high mortality resulting in a major health impact (Christian, 2013). Hantavirus weaponization is speculative as there are no known major weapon development programs occurring. However, their weaponization remains attractive due to their potential to cause high mortality (up to $60 \%$ during the height of the 1993 Four Corners outbreak), and their ability to target young and healthy adults in risk occupations such as agriculture and forestry (Hjelle et al., 1994; de St Maurice et al., 2017). Ultimately, the priority difference between the two doesn't make one any less meaningful, as the employment of bioagents from any category of bioweapon could have a public health impact with implications to national security.

Category considerations of biological agents vary between the Centers of Disease Control and Prevention (CDC) and the US National Institute of Allergy and Infectious Diseases (NIAID) based upon circumstance of the infectious agent. The CDC assesses bioagent risks in support of US public health systems and primary healthcare providers and how, based upon 
TABLE 1 | Centers for Disease Control and Prevention (CDC) Biological Agent Categories (Christian, 2013; CDC, 2018).

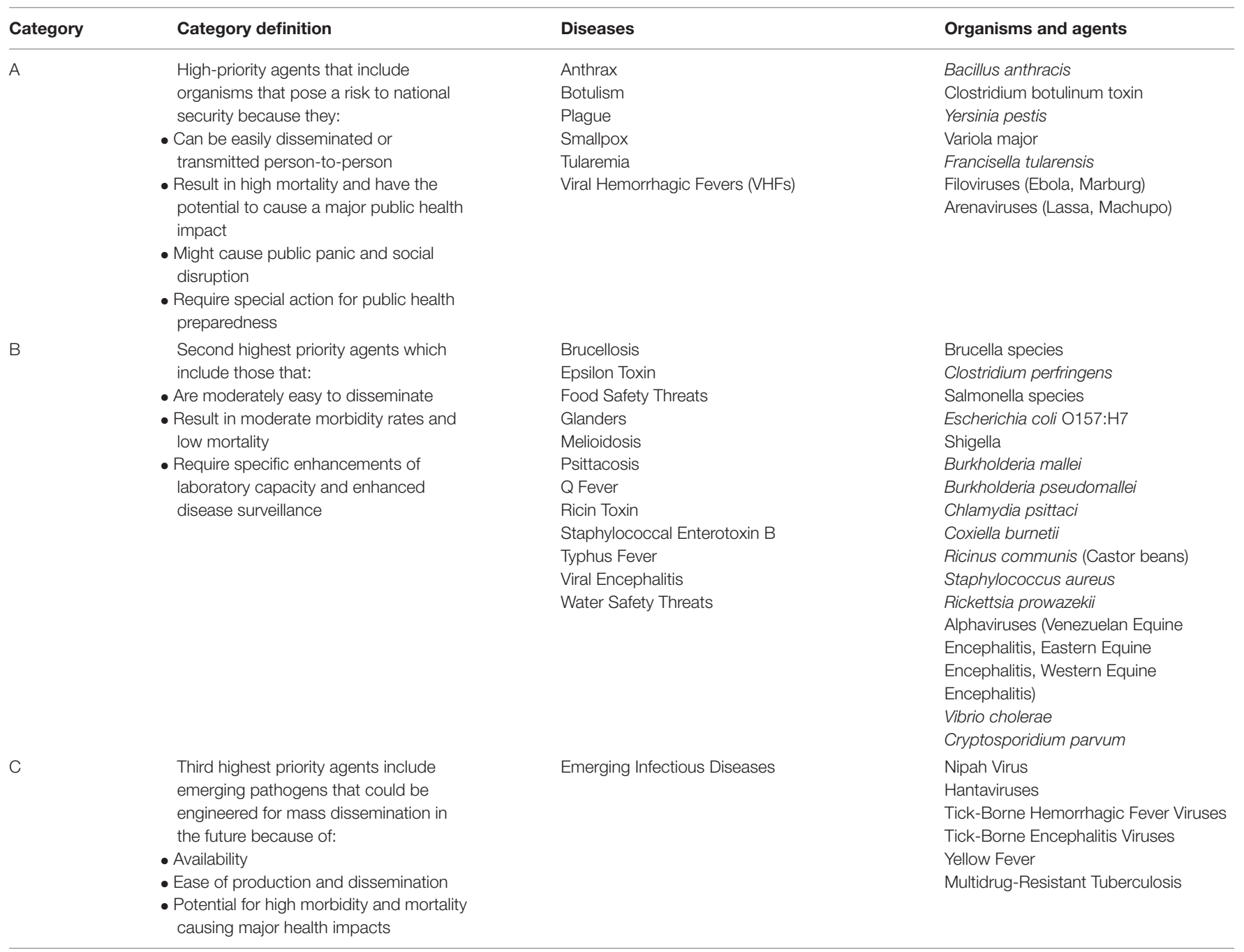

the categorization, they should respond to biological agents and pathogens including those that seldom occur in the US (CDC, 2018). NIAID's categories refer to documented priority pathogens A, B, and C, and emerging infectious diseases defined as those that have newly appeared in a population or have existed but are rapidly increasing in incidence or geographic range (NIAID, 2018). There is much categorical confusion though for hantaviruses, and specifically New-World Hantaviruses such as Sin Nombre orthohantavirus (SNV), as to what priority of a bioagent and subsequent threat they pose (Mir, 2010; Mittler et al., 2019). Hantaviruses as a whole are categorized as emerging viruses along with Nipah Virus in the CDC as Category C Pathogens; whereas NIAID places hantaviruses as part of the Category A Pathogens (CDC, 2018; NIAID, 2018). Hantaviruses, specifically Old-World Hantaviruses causing HFRS, are listed in Category $\mathrm{C}$ due to their shared symptoms to other agents causing Viral Hemorrhagic Fever (VHF) that cause capillary leakage syndrome and hemorrhaging (Clement, 2003). Category $\mathrm{C}$ retains the lowest priority of risk to national security and ultimately the lowest potential as a biowarfare agent.
However, it doesn't diminish the risk that hantaviruses pose globally. With their widespread nature, being present on every continent except for Australia and Antarctica, hantaviruses continue to pose a risk to human systems and activities that closely engage with their rodent-specific reservoirs including military personnel, agricultural workers, and transport industries including warehouse and shipping staff (Forbes et al., 2018). This review paper seeks to clarify the categorization of hantaviruses as bioweapons as well as to define the practicality of employing hantaviruses, specifically HCPS-causing SNV and Andes Virus (ANDV), as novel bioagents against modern militaries and industries.

\section{HCPS-CAUSING NEW-WORLD HANTAVIRUSES}

The hantavirus genus forms part of the Bunyavirus family and is composed of well-defined serotypes that are each associated with a specific primary rodent reservoir (Spiropoulou et al., 


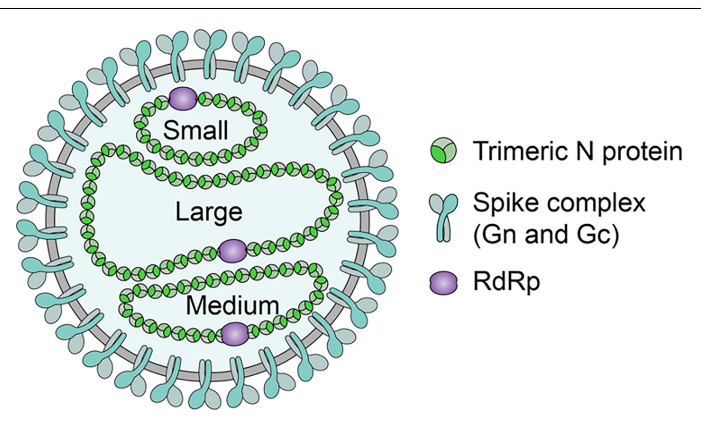

FIGURE 2 | Hantavirus structure. Hantaviruses are enveloped with a lipid bilayer containing Glycoprotein spikes assemblies comprised of Gn and Gc Glycoproteins. Contained within the envelope are the equimolar amounts of $N$ Protein packaged S (small), M (medium), and L (large) segments VRNA, which are associated with an RdRp (Hussein et al., 2011; Hepojoki et al., 2012). SNV structure is generally spherical with a dense envelope (Goldsmith et al., 1995). N Protein forms trimers that selectively encapsidates the negative-sense vRNA into RNPs and assists in its panhandle formation for packaging (Mir and Panganiban, 2004).

1994; Avsic-Zupanc et al., 2019). The hantavirus genome is tripartite and is composed of three segments of negative-sense, single-stranded RNA (Nichol et al., 1993). The three segments are organized by size and are designated as the Large (L), Medium (M), and Small (S) segments since the tripartite genome lengths are generally $6.6,3.7$, and $2.1 \mathrm{~kb}$ for the $\mathrm{L}, \mathrm{M}$, and $\mathrm{S}$ segments respectively (Figure 2) (Plyusnin et al., 1996). The genomic L, M, and S segments encode for the $250 \mathrm{kDa}$ RNAdependent RNA polymerase (RdRp), 125-127 kDa Glycoprotein Precursor (GPC) and subsequent co-translationally cleaved Gn and Gc Glycoproteins, and the $48 \mathrm{kDa}$ Nucleocapsid (N) Protein respectively (Nichol et al., 1993; Kamrud and Schmaljohn, 1994; Chizhikov et al., 1995). SNV, amongst other hantaviruses with the exception of Haantan Virus (HTNV), Seoul Virus (SEOV), and Dobrava Virus (DOBV), have an open reading frame (ORF) for a putative Non-Structural Protein (NSs ranging between 7 and $10 \mathrm{kDa}$ in size) (Plyusnin et al., 1996). Additionally, each genomic segment is flanked by $5^{\prime}$ and $3^{\prime}$ Non-Coding Terminal Regions (NTRs) which are common to Bunyaviruses (Amroun et al., 2017).

The L Segment's RdRp acts as the RNA transcriptase and replicase, transcribing mRNA and replicating the genomic RNA using the positive-sense RNA as an intermediate (Kukkonen et al., 2005) (Figure 3). Hantaviral RNA segments are each associated with the $\mathrm{RdRp}$ and are packaged within a ribonucleoprotein complex formed by the N Protein (Hepojoki et al., 2012). The RdRp is responsible for vRNA transcription and replication, additionally retaining endonuclease activity which is used to cleave the $5^{\prime}$-termini of host mRNA to act as a primer which initiates viral mRNA transcription in a process called capsnatching and prime and realignment (Kukkonen et al., 2005). This occurs in conjunction with the N Protein which is found to form an N-RdRp complex for RNA synthesis whilst also binding to mRNA caps by recognizing a five nucleotide sequence adjacent to the $5^{\prime}$ cap for high-affinity binding (Mir et al., 2010; Cheng et al., 2014). During cap-snatching, the viral RdRp binds to methylated capped $5^{\prime}$ ends of host mRNAs and cleaves them for use as a primer for mRNA synthesis with a preference for host mRNAs that contain a Guanine prior to the cleave site (Garcin et al., 1995). The prime and realignment follow the methylated 5 ' cap whose aforementioned $\mathrm{G}$ nucleotide at the -1 position would align opposite a Cytosine nucleotide at the +3 position on the negative-sense vRNA genome. After the primer is extended up to 3 nucleotides, the nascent chain will realign to shift the original $3^{\prime}$ Guanine back to the -1 position ultimately generating two to four UAG repeats (Hutchinson et al., 1996).

Pathogenic hantaviruses retain glycoproteins that target and interact with the $\beta_{3}$ chain of Integrins that is especially abundant as a surface receptor on endothelial cells, dendritic cells (DC), and platelets where they are critical in maintaining capillary integrity (Gavrilovskaya et al., 1998). Endothelial cells are ubiquitously infected throughout the body by HFRS and HCPS-causing hantaviruses, however, pulmonary endothelial cells are the primary targets during HCPS infections with DCs and platelets being involved in the pathogenic process of vascular leakage and thrombocytopenia (Connolly-Andersen et al., 2014, 2015; Ermonval et al., 2016). Hantaviruses inducing HCPS employ $\alpha 11 \beta 3$ Integrins with hantaviruses inducing HFRS employing $\alpha \nu \beta 3$ Integrins for entry both of which are $\beta_{3}$ Integrins; $\alpha 5 \beta 1$ Integrins are employed by non-pathogenic hantaviruses (Gavrilovskaya et al., 1998, 1999). The hantavirus virion is itself enveloped retaining a lipid bilayer whose membrane is $5 \mathrm{~nm}$ thick and studded with the Gn and Gc glycoprotein spike assemblies that project $10 \mathrm{~nm}$ from the membrane in fourfold rotational symmetry (Hepojoki et al., 2012). The virion's shape appears as a rounded, pleiomorphic particle ranging between 70 and $350 \mathrm{~nm}$ in diameter (Plyusnin et al., 1996; Hepojoki et al., 2012). The M Segment retains a five amino acid sequence (WAASA) that precedes the co-translational cleavage site for the GPC which is conserved across all hantaviruses (Spiropoulou et al., 1994).

The N Protein's role is multifaceted, but is primarily involved in the encapsidation of the vRNA and protects it from host cellular nucleases by binding selectively to Hantaviral panhandle structures (Mir and Panganiban, 2005; Mir et al., 2010). Each SNV segment possesses conserved terminal sequences at the $5^{\prime}$ and $3^{\prime}$ NTRs that are capable of complementarily basepairing to form panhandle structures (Chizhikov et al., 1995). These conserved sequences, consisting of 14-17 nucleotides, were found to be highly conserved throughout the hantavirus genus, being comprised of the following sequence at the $3^{\prime}$-termini: $3^{\prime}$ AUCAUCAUCUGAGG-5'; and the following sequence at the 5'-termini: 5'-UAGUAGUAU(G/A)CUCC-3' (Chizhikov et al., 1995). Trimeric N Protein subsequently recognizes these panhandle structures with specificity and encapsidates the vRNA, with trimerization being required for high-affinity binding (Mir and Panganiban, 2004; Brown and Panganiban, 2010). The N Protein is also genus-specific and can bind to vRNA and cRNA of other hantavirus species (Mir et al., 2006). The N Protein's RNA chaperone roles are employed when interacting with the vRNA and its panhandle structures, assisting in the dissociation of the RNA duplexes and initiating replication by the RdRp (Kukkonen et al., 2005; Mir and Panganiban, 2006a). The N Protein's RNA 


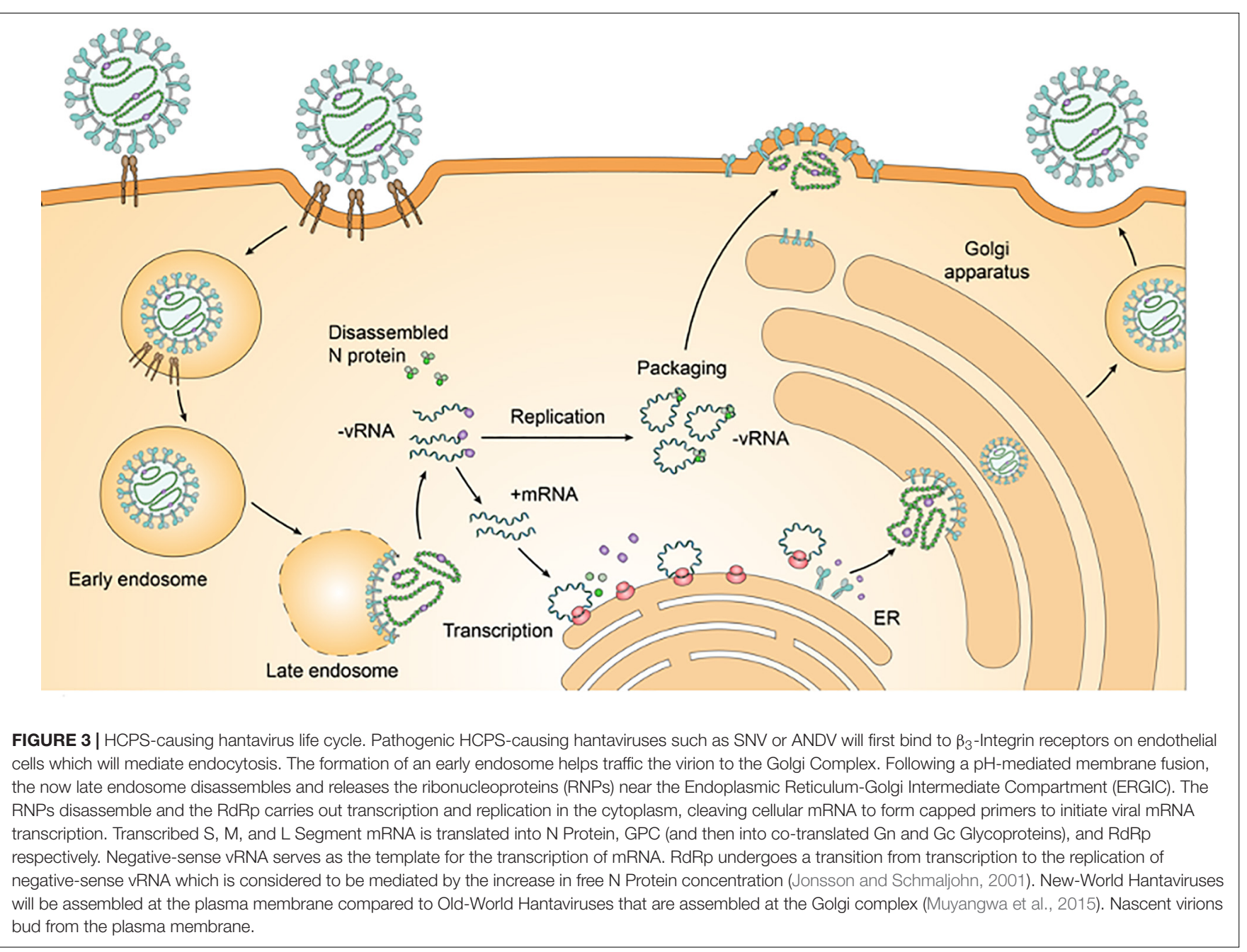

chaperone properties also enable it to bind to misfolded vRNA, refolding it to allow the high-ordering of panhandle structures to form and to prevent RNA structures from falling into inoperable kinetic traps (Mir and Panganiban, 2006b).

SNV and ANDV are the two major causative agents of HCPS, with ANDV occurring in South America which is spread by the Sigmondontinae subfamily and mainly by Oligoryzomys longicaudatus or the long-tailed pygmy rice rat reservoir (BeltranOrtiz et al., 2017; Astorga et al., 2018). Before the presence of SNV, hantaviruses were not considered to be a serious public health threat as other hantaviruses like Prospect Hill Virus (PHV) and HFRS-causing SEOV have been found in a number of US cities (Spiropoulou et al., 1994). The disease took significant attention when the respiratory illness of HCPS was first observed in the Four Corners region of the United States in 1993, with the outbreak causing upwards of $75 \%$ mortality in healthy adults between the ages of 20-40 years (Nichol et al., 1993). The deer mouse (Peromyscus maniculatus) was identified as the primary rodent reservoir for SNV; it is one of the most abundant small mammals in North America, found not just exclusively to the Canadian prairies and the American Midwest (Spiropoulou et al., 1994). The emergence of SNV is likely due to environmental factors that favored the natural reservoir of deer mice to increase, allowing for increasing opportunities for human infection (Schmaljohn and Hjelle, 1997). The reoccurrence and increased rodent-human contact can be attributed to increased food availability from erratic weather conditions that produced higher precipitation and warmer climates (Watson et al., 2014). Due to climate change and its impact of lowering biodiversity caused a dilution effect that altered reservoir behavior and forced population migration, and the ultimate spread of the infectious agents to human systems (Watson et al., 2014).

The reservoirs themselves can spread the virus horizontally, being nearly asymptomatic but chronically infected (Guterres and de Lemos, 2018). HFRS and HCPS are generally acquired from the inhalation of aerosolized excreta including feces, urine, and saliva infected with hantavirus (Kariwa et al., 1998; Kallio et al., 2006; Godoy et al., 2009; Warner et al., 2019a). This can also include the direct contamination of food or household articles with rodent excreta as well as virion particles shed from rodent skin and fur (Yanagihara et al., 1985; Zaki et al., 1995). However, SNV transmission requires direct contact between $\mathrm{SNV}$-infected rodents and humans as contaminated cages proved to be ineffectual in transmitting the disease horizontally to 
uninfected deer mice (Warner et al., 2019a). ANDV is unique in that it can transmit hantavirus through person-to-person contact (Alonso et al., 2020). No other hantavirus exhibits the property of person-to-person transmission, which makes ANDV a preferable candidate for weaponization, which would take advantage of the additional spread mechanism. No personto-person hantavirus infections have been reported in North America, making SNV less effective as a bioweapon, comparably (Hartline et al., 2013). The person-to-person transmission of ANDV occurs mainly in family clusters or close activities with infected persons during the disease's prodrome phase, occurring during the interval of 12-27 days between the initial exposure and the onset of symptoms (Figueiredo et al., 2014). Sexual partners have a higher risk of infection compared to non-sexual partners (Martinez-Valdebenito et al., 2014).

Hantaviruses generally enter cells utilizing a clathrindependent pathway which follows the formation of an early endosome and subsequent low-pH initiating dissolution of the late endosome for infectious entry (Jin et al., 2002) (Figure 3). SNV and ANDV can enter endothelial cells primarily by a receptor-mediated endocytic pathway involving $\beta_{3}$-integrins but also a clathrin-dependent pathway (Gavrilovskaya et al., 1998; Chiang et al., 2016). New-World Hantaviral replication occurs predominately in pulmonary endothelial cells which have exhibited the highest viral loads, resulting in increased vascular permeability (Zaki et al., 1995). Macrophages, follicular DCs, and DCs are also known to replicate the Hantaviral genome with the virus also being found in human tissues of the kidney, spleen, pancreas, lymph nodes, skeletal muscles, heart, intestines, adipose tissue, urinary bladder, and brain (Borges et al., 2006). Replication occurs in the cytoplasm with the budding of the Hantaviral virion occurring in the Endoplasmic Reticulum Golgi Intermediate Complex (ERGIC); SNV uniquely, but principally, buds from the plasma membrane (Goldsmith et al., 1995; Vapalahti et al., 2003) (see Figure 3).

Hantavirus infections activates the innate immune system with downstream effects that induces disease. The innate immune system recognizes pathogens through their interaction with Pattern Recognition Receptors (PRRs) which are expressed by many cell types, including endothelial and epithelial cells. Viruses present Pathogen-Associated Molecular Patterns (PAMPs) which are recognized by PRRs which activate signaling cascades and transcription factors that modulate the expression of type I Interferons and Interferon-Stimulating Genes (ISGs) involved in antiviral functions. Toll-like Receptors (TLRs) and Retinoic acid-Inducible Gene-I (RIG-I), including the RIGI-like receptor Melanoma Associated Gene 5 (MDA5), are PRRs that are involved in the recognition of pathogenic RNA viruses by binding to vRNA (Kawai and Akira, 2007). Binding of PAMPs in the form of vRNA to TLRs and RIGI receptors activates transcription factors $N F-\kappa B$ and IFN Regulatory Factor 3 and 7 (IRF3/7) that are translocated into the nucleus to bind to ISGs that are used to express Interferons (IFN) (Sen and Sarkar, 2005; Kato et al., 2006). Type I Interferons $($ IFN- $\alpha / \beta)$ are critical regulators of immune cell activation, development toward antiviral activity, cell growth, and apoptosis and are involved in stimulating the Janus Kinases and signal and activators of transcription pathways (JAK/STAT) (McNab et al., 2015).

New World Hantaviral proteins antagonize virus recognition by suppressing the JAK/STAT signaling pathways with ANDV utilizing its N Protein and the GPC to disrupt antiviral activity while SNV employs its GPC alone (Levine et al., 2010). The $\mathrm{N}$ Protein of hantaviruses has been reported to inhibit IFN activity and NF- $\kappa \mathrm{B}$ activation, with ANDV N Protein inhibiting signaling responses instigated by RIG-I and MDA5 and upstream IRF3 phosphorylation (Taylor et al., 2009; Cimica et al., 2014; Pan et al., 2015). Both HTNV and ANDV N Proteins inhibit Tumor Necrosis Factor $\alpha$ induced activation from NF- $\kappa$ B by preventing the transcription factors translocation into the nucleus (Taylor et al., 2009). Additionally, reports identified the highly conserved domains of the Glycoprotein Gn's cytoplasmic tail which also functions in early IFN responses by blocking IRF3 and NF$\kappa \mathrm{B}$ activation and subsequent downstream antiviral function of the early immune response (Matthys and Mackow, 2012; Mackow et al., 2014). Vero cell lines are used preferably to isolate and amplify hantaviruses since they are deficient in IFN-I and IFN-II expression and will not elicit an immune response to infection although New-World Hantaviruses have been shown to elicit IFN- $\lambda$ activation in Vero cell lines (Emeny and Morgan, 1979; Prescott et al., 2010; Seto et al., 2011). Pretreatment of IFN- $\lambda$ s have been shown to induce antiviral activity against HTNV infection by activating the JAK-STAT pathway in A549 cells ( $\mathrm{Li}$ et al., 2019). Pathogenic hantaviruses tend to regulate the early induction of IFN to replicate successfully with pretreated Type I IFNs only being successful shortly after infection (Matthys and Mackow, 2012).

\section{SYMPTOMS}

Patients suffering from HCPS generally present fever, headache, muscle aches, and chills as well as leukocytosis and thrombocytopenia, which rapidly progresses to more severe respiratory diseases (Schmaljohn and Hjelle, 1997). After 4-10 days, individuals infected with HCPS-causing hantaviruses developed influenza-like illnesses followed by rapidly progressing pulmonary edema caused by pulmonary capillary leak syndrome, resulting in respiratory dysfunction and shock (Zaki et al., 1995; Schmaljohn, 2009). HCPS is particularly important because unlike other respiratory diseases, it occurs in young, healthy adults (Beltran-Ortiz et al., 2017). Death occurred 2-10 days after the onset of the illness within almost $50 \%$ of patients observed (Borges et al., 2006). Although HCPS shares some similarities with HFRS, like the febrile prodrome and capillary leakage, the kidneys are largely unaffected with capillary leakages occurring exclusively in the lungs and resulting in shock and cardiac complications despite sufficient tissue oxygenation (Schmaljohn and Hjelle, 1997).

\section{VACCINES AND THERAPEUTICS}

There are no US FDA-approved vaccines available for hantavirus infections, however, there are a variety of live-attenuated vaccines 
(Hantavax), DNA vaccines, subunit vaccines, and virus-like particle (VLP) vaccines that all demonstrate varying degrees of effectiveness (Schmaljohn et al., 1992; Cho and Howard, 1999; Choi et al., 2003; Ying et al., 2016; Liu et al., 2019). The Hantavax vaccine is available and is instituted in the Republic of Korea, with effectiveness against HFRS-causing hantaviruses such as HTNV and SEOV and resulting in a subsequent reduction in HFRS-related hospitalizations (Yi et al., 2018). However, its immunogenicity is dependent on early booster vaccinations in tandem with its two-dose primary vaccination which was demonstrated to provide timely protection to high-risk groups like farmers and those in the military (Song et al., 2016). DNA vaccines that use recombinant Vesicular-Stomatitis virus vectors expressing SNV and ANDV glycoproteins in Syrian hamster models were also effective at eliciting an immune response and conferred protection against lethal ANDV (Warner et al., $2019 b)$. DNA vaccines are preferable because they can present the most immunogenic antigens to the host immune system whilst avoiding the need to propagate inactivated hantaviruses that are universally difficult to grow, isolate, and purify, with many DNA vaccines expressing Old-World Hantavirus glycoprotein genes and eliciting successful immune responses in hamster models (Schmaljohn et al., 2014).

There are currently no US FDA-approved post-exposure therapeutics against Hantaviral infections, however, there are treatment strategies present to manage HFRS and HCPS (Liu et al., 2019). Virus-targeting antivirals including antiviral drugs, antibodies, or novel-small molecules are designed to block hantavirus entry or to reduce viral replication. Ribavirin is an effective anti-Hantaviral drug that affects the biological function of RdRp and has had some success in treating HFRS cases including protecting Syrian hamsters in lethal HCPS models (Safronetz et al., 2011; Warner et al., 2019b). Ribavirin was effective at preventing lethal HCPS disease by having an inhibitory effect on ANDV replication (Safronetz et al., 2011). Ribavirin also inhibits SNV in vitro while the pre-treatment of deer mice followed by daily therapy of Ribavirin reduced SNV infection and viral RNA synthesis (Medina et al., 2007). However, Ribavirin has some limitations as at high doses it is toxic to humans and animals and causes anemia (McKeeJr., Huggins et al., 1988; Chapman et al., 1999). It was also noted that intravenous Ribavirin was ineffective at treating HCPS-patients after the onset of the cardiopulmonary phase (Chapman et al., 1999; Mertz et al., 2004). Antivirals also function effectively only during the early infection stage and not after the start of viremia (Brocato and Hooper, 2019). This could largely be attributed to the uncontrolled immune response which predominates the Hantaviral pathogenesis process after immediate infection (Liu et al., 2019). The Hantaviral prodrome phase can also be difficult to differentiate from other febrile illnesses, which may benefit infection by impeding proper identification and treatment (Brocato and Hooper, 2019). Another antiviral is Favipiravir that has shown broad-spectrum antiviral activity against RNA viruses including Bunyaviruses, being better than Ribavirin in that it is well-tolerated in humans without hemolytic anemia related side effects (Safronetz et al., 2013). Favipiravir was evaluated using in vivo studies for both SNV and ANDV infected hamster lethal disease models and resulted in complete survival as well as the reduction of ANDV RNA and antigens in the blood and lungs, although it was no longer effective after the onset of viremia in delayed antiviral treatment studies (Safronetz et al., 2013; Brocato and Hooper, 2019).

Hantaviruses can be inactivated by heat (sustained $30 \mathrm{~min}$ at $60^{\circ} \mathrm{C}$ ), detergents, UV radiation, organic solvents, and hypochlorite solutions (Avsic-Zupanc et al., 2019). Despite this, hantaviruses are fairly durable and unexpectedly stable outside of a host, being able to survive longer than 10 days at room temperature and more than 18 days between the -20 and $4^{\circ} \mathrm{C}$ range (Vaheri et al., 2013). For most hantaviruses, contaminated dust or aerosols can transmit the virus to other rodents for up to 15 days after being excreted with viral infectivity in the culture being lost within 5-11 days when incubated at $23^{\circ} \mathrm{C}$ (Kallio et al., 2006; Hardestam et al., 2007). 70\% Ethanol completely inactivates Bunyaviruses broadly, with HTNV being partially resistant to $30 \%$ Ethanol (Hardestam et al., 2007). These are largely chemical prophylactics designed to maintain sanitation and treat hantavirus-contaminated facilities and would create risk for livestock and personnel unprotected by strong detergents or hypochlorite solutions. Consequently, the absence of any effective vaccines or therapeutics makes hantavirus infections particularly dangerous to those working or operating in risk environments including agriculture, forestry, mining, and military operations.

\section{BIOWARFARE POTENTIAL OF HCPS-CAUSING HANTAVIRUSES}

Hantaviruses have generally remained in the Category C position from the CDC and biodefense categorizations which is different from the laboratory biosafety criteria summarized in Table 2 . Hantaviruses are considered a biosafety level 3 bioagent with regards to NIH and across the European Union (EU), with the exception of HCPS-causing hantaviruses in the EU being considered a level 2 because their criteria differ with regards to an agent that causes human disease and might be a hazard to workers, but is unlikely to spread to the community, and there is usually effective prophylactic treatment available (Tian and Zheng, 2014). For comparison, the NIH treats Ebola virus as a level 4; Bacillus anthracis as a level 2; SARSassociated coronavirus (SARS-CoV) as a level 3; and Human

TABLE 2 | Biosafety categorization based upon the National Institute of Health (NIH) Criteria (Tian and Zheng, 2014).

\section{Requirements}

Agents that are not associated with disease in healthy adult humans. Agents that are associated with human disease which is rarely serious and for which preventive or therapeutic interventions are often available.

3 Agents that are associated with serious or lethal human disease for which preventive or therapeutic interventions may be available (can cause high individual risk but low community risk).

$4 \quad$ Agents that are likely to cause serious or lethal human disease for which preventive or therapeutic interventions are not usually available (can cause high individual risk and high community risk). 
Immunodeficiency Virus (HIV) as a level 3; regardless of the biosafety levels, both Ebola Virus and Anthrax are considered very high biothreats with hantavirus being a high threat in the EU (Tian and Zheng, 2014). BSL 3 laboratory requirements are intensive, especially for highly pathogenic diseases that can cause harm to materials and personnel. Incidentally, for a research or industrial laboratory to study hantaviruses they require: direct physical protection from the virus in the form of PPE including gloves, masks, gowns, respiratory protection, and positive pressure ventilation suits; Biosafety Cabinets (BSC) as primary containments to isolate the pathogen and the user; secondary containments to mitigate or prevent the pathogen's presence outside the BSC and its exit outside BSL 3 containment; and physical barriers in the form of walls, fences, or exclusion zones to prevent outside contamination (Pastorino et al., 2017). The initial infrastructural costs and maintenance of BSL 3 containment protocols would be prohibitively expensive and complex for uninitiated bioterrorist organizations making its development by smaller, resource poor organizations unfeasible.

Hantaviruses are cited as being possible bioweapons that can be used against humans. When focused on specific serotypes of hantavirus, like SNV and ANDV, it becomes apparent that with their high mortality rate and rapid disease course with serious cardiopulmonary symptoms New-World Hantaviruses as opposed to HFRS-causing Old-World Hantaviruses are the more severe threat (Jonsson et al., 2008). Since HCPS-causing New-World Hantaviruses exhibit a high mortality (up to $50 \%$ in older patients) but low morbidity, it would preclude them from the Category B bioweapons which specifically are classified by their moderate morbidity and low mortality rates (Drebot et al., 2015). This causes SNV or ANDV bioagents to be assessed within Category $\mathrm{A}$ or $\mathrm{C}$ terms, although the moderate dissemination quality of Category B is reflective of hantaviruses and their limited projection by aerosols and rodents. Nevertheless, successful bioweapons have very strict requirements listed in Table 3.

\section{HCPS-Causing Reservoirs Are Available and Are Affected by Environmental Factors}

The presence of SNV-infected deer mice across the American Midwest is fairly high as seroprevalence of SNV antibodies were discovered in $38 \%$ of captured rodents in Indiana, with up to $25 \%$ of seroprevalence in the western US and $7 \%$ in the eastern US (Berl et al., 2018). SNV-infected deer mice are somewhat discontinuous across Canada, but are located in every Canadian province as well as the Yukon territory and tend to display greater than $30 \%$ seroprevalence in large, close proximity populations (Drebot et al., 2015). Seropositivity of ANDV was prevalent across South America, particularly Patagonia in Chile and Argentina with antibodies being present at $5.9 \%$ specifically for Oligoryzomys longicaudatus (Medina et al., 2009; Astorga et al., 2018). Male deer mice have a higher seroprevalence of SNV antibodies compared to female deer mice which is the same for Sigmodontinae species infected with ANDV (Padula et al., 2004; Medina et al., 2009). Consequently, acquiring HCPS-causing Hantaviruses is relatively easy and requires access to natural habitats and peridomestic environments that harbor the rodent reservoir. The relative abundance of HCPS-causing rodents will be dependent on precipitation but overall maintain high ecological densities (Jonsson et al., 2010).

Climate change will also have impacts to the acquisition and maintenance of Hantaviral reservoirs. Rodent population dynamics are particularly affected by a combination of unusually high rainfall followed by drought which is evidenced by the 1993 US Four Corners outbreak which was preceded by a dramatic increase in rainfall following the 1992-1993 El Niño warming phase (Gubler et al., 2001). These favorable conditions led to increases in rodent food sources and a significant increase in rodent population which took advantage of the Four Corners' environment which provided favorable habitats conducive for the growth of P. maniculatus (Engelthaler et al., 1999). This likely contributed to rising deer mouse populations which resulted in increased exposure of rodent-human contact, similar to the PUUV outbreak in Northern Europe which was also precipitated by an unusually wet spring season which affected bank vole populations beneficially (Spiropoulou et al., 1994). The increase in North and Western European vole populations is adjusted by elevated average temperatures which improves mast production. Higher densities of rodents benefited from high seed production, itself improved by warmer summer conditions which benefited winter survival and subsequent spring breeding (Klempa, 2009). Incidentally, human-reservoir contact increased as the reservoir population increased.

Bioterrorist cells have the potential to take advantage of high rodent population densities. Having higher populations of asymptomatic but chronically infected rodent specimens can be utilized in either a one-target distribution model, or as a means to generate a critical concentration of passaged virions to achieve a weaponizable aerosol. Both methods would require a large-scale capture and maintenance of rodents, with the latter being more onerous in the process of passaging and isolating the hantavirus. However, the role of climate change provides access for bioterrorist groups to acquire the virus through freely available infected rodents because of their increased populations. This can change depending on the effects of human activity which is being accelerated by agricultural expansion, deforestation, land reclamation, irrigation projects, and infrastructural developments (Klempa, 2009).

\section{Difficulty in Cell Culturation Reduces Ease of Production}

Hantaviruses have historically been very difficult to isolate and grow in both cell culture and animal models, which have limited their ability to be previously concentrated and weaponized (Chizhikov et al., 1995). The first successful passage of HTNV in a laboratory setting occurred in 1978, and the first successful passage and isolation of SNV occurred in 1994 (Elliott et al., 1994). The virus itself requires passaging by rodent-to-rodent transmission followed by cell culturing in Vero E6 cells, with the virus replicating specifically in $P$. maniculatus cells despite repeated attempts of using RT-PCR to amplify positive hantavirus 
TABLE 3 | Summary of ideal Biological Warfare Requirements adapted and modified from Meyer and Morse (2008) and Christian (2013).

\begin{tabular}{|c|c|c|c|}
\hline & Requirements & Risk & Condition \\
\hline 4 & Effective Transmission Pattern and Routes of Entry & Medium & $\begin{array}{l}\text { Inhalation of both ANDV and SNV } \\
\text { Person-to-Person Transmission of ANDV }\end{array}$ \\
\hline 5 & Effective Delivery Systems and Mode of Transportation & Medium & $\begin{array}{l}\text { Effective Deployment Indoors } \\
\text { Rodent Delivery is Onerous and Resource Intensive }\end{array}$ \\
\hline 8 & The Ability to Incapacitate or Kill Target Host & Medium & $\begin{array}{l}\text { High Mortality Rate } \\
\text { Low Morbidity Rate }\end{array}$ \\
\hline 9 & $\begin{array}{l}\text { Appropriate Particle Size for Aerosolization and } \\
\text { Airborne Transmission }\end{array}$ & Medium & $\begin{array}{l}\text { Can be Aerosolized } \\
\text { Airborne Efficiency within Closed Environments }\end{array}$ \\
\hline 10 & $\begin{array}{l}\text { The Ability to be Disseminated in Food or Water } \\
\text { Supplies }\end{array}$ & High & $\begin{array}{l}\text { Can Contaminate Food and Water as well as } \\
\text { commercial products }\end{array}$ \\
\hline 11 & $\begin{array}{l}\text { Logistic Requirements to Manufacture and Disperse } \\
\text { Bioagents which include Infrastructural and Financial } \\
\text { Support, Expertise, and Organizational Capabilities }\end{array}$ & Low & $\begin{array}{l}\text { Intensive Laboratory Equipment and High Expertise } \\
\text { Requirements } \\
\text { High Costs } \\
\text { Deployment of Infected Rodents Reservoirs is } \\
\text { Demanding }\end{array}$ \\
\hline
\end{tabular}

Table also includes the capabilities required by conventional or unconventional militaries to conduct and deliver a bioagent attack. Note that the ranking is unimportant. We also describe the risks associated with bioweapons requirements as they pertain to the feasibility of developing and deploying New-World Hantaviruses. Risk is graduated with regard to Low, Medium, and High.

from human or rodent samples (Elliott et al., 1994). Isolation from the reservoir host or from diseased human patients tends to require extensive blind passaging in cell culture to acquire adequate viral titres for characterization studies, with viral propagation being observed to elicit reduced infectivity in natural rodent reservoirs (Fulhorst et al., 1997; Galeno et al., 2002). SNV propagation in Vero cultures seems to cause mutations in the RdRp which potentially attenuates the virus and makes it less virulent (Safronetz et al., 2014). The problem arises from attempting to adapt the viruses to new hosts through sequential passaging from animal to animals as well as amplifying the virus in large stocks of Vero cell lines which have resulted in the attenuation of the viral culture (Prescott et al., 2017). Conversely, attempts at experimentally recreating signs and symptoms of HFRS or HCPS in a non-human primate model demonstrated that various non-human species can be infected by the disease but they do not develop obvious symptoms. This trend is observed in the attenuation of the Old-World Hantavirus PUUV in cell culture due to point mutations occurring in its S Segment. PUUV's propagation in Vero E6 cells replicated with high efficiency but did not retroactively infect its natural reservoir host the bank vole (Clethrionomys glareolus) or cause severe disease in cynamalogous macaques (Lundkvist et al., 1997; Klingström et al., 2002; Eckerle et al., 2014). Comparatively, SNV propagated in deer mice after passaging in Vero cell lines elicited severe disease in its non-human primate model of rhesus macaques (Safronetz et al., 2014).

The previous reporting of hantavirus being difficult to isolate have also been attributed to the low concentrations of infectious virion particles extracted from the clinical or wild-caught infected rodents, with virion replication peaking at the time of death for the HCPS-infected human patients (Chizhikov et al., 1995). Combined with the slow and non-cytopathic growth of hantaviruses in cell culture are considerations as to why isolation becomes onerous (Chizhikov et al., 1995). Passaging has been successful in non-rodent, non-human primate models involving rhesus macaques, but they had to be previously passaged in deer mice to maintain virulence and infectivity which increases the requirements for weaponization (Safronetz et al., 2014; Warner et al., 2019a). Furthermore, SNV propagation in Vero cultures seems to cause mutations in the RdRp which potentially attenuates the virus and makes it less virulent 
(Safronetz et al., 2014). Consequently, the significant absence of any strong disease models outside of macaques and Syrian hamsters poses a challenge for weaponization, as the inability to replicate a similar human disease progression in primates from passaged and isolated virions will hinder the lethality of any engneered bioweapon.

Although tough and resource demanding, concentrating hantaviruses is not impossible and may become more efficient with newer technologies and techniques as Warner et al. (2019a) demonstrated. A way to increase viral stocks is to avoid using the standard intramuscular model of infection and instead use the intraperitoneal infection of deer mice which was demonstrated to produce SNV stocks with high viral RNA copy number (Warner et al., 2019a). New immunotherapies methods leading toward lethal disease models are also helping to increase the viral load as the infection of immunocompetent Syrian hamsters with cell-cultured SNV resulted in lower levels of viral dissemination compared to immunocompromised hamsters (Brocato et al., 2014; Vergote et al., 2017). Improvements in viral isolation for biological characterization studies has been conducted with HTNV and PUUV in suckling mice and Syrian hamsters respectively because of their sensitivity to infection (Seto et al., 2011; Li et al., 2013). There is still a reliance on Vero cell lines for viral propagation which has its own challenges. Vero E6 cells have been shown to produce an IFN- $\lambda$ response to Hantaviral infection consequently reducing viral yields and affecting their quality (Prescott et al., 2010). The challenge of viral isolation, culturing, and modification in recent years has become relatively easy as indicated by the isolation and sequencing of the SARS-CoV-2 virions which demonstrates that synthetic biology methods are available for facilitating virion production which could include reverse engineering (Thao et al., 2020). Hantavirus components and virions as well as pseudovirions are already produced by passaging in Vero E6 cell lines, with RT-PCR methods and Vesicular Stomatitis Virus vectors being employed for sequencing and for the detection of hantavirus infection through the presence of their neutralizing antibodies (Elliott et al., 1994; Higa et al., 2012; Niskanen et al., 2019).

Additionally, given the rise in genetic engineering tools and techniques such as TALEN and CRISPR/Cas9, the ability to synthetically engineer more pathogenic bioagents is available (Benjamin et al., 2016). CRISPR/Cas9 was employed to reduce HIV viral replication in infected T-cells, and could potentially be employed to increase virulence and viral replication for other pathogens including HCPS-causing hantaviruses (Ophinni et al., 2018). Incidentally, the limitation of culturing hantaviruses virions now may be improved overtime with developments in gene editing and Do-It-Yourself technologies which have made sophisticated techniques more accessible to conventional militaries and terrorist organizations (Quetier, 2016).

\section{Susceptible Targets Conventional Warfare Settings}

Militaries and hantaviruses have a deep history which is largely tied with the operation of war and the requirements that are needed to support it (Johnson, 2001). One important factor of militaries is their strength component, comprised of large bodies of soldiers congregating in theaters of operations for extended periods of time. This has the unfortunate consequence of consolidating resources, especially food that has the tendency to attract animals such as rodents and insects, as well as disrupting natural habitats that affect ecosystems and the reservoirs that inhabit them (Lawrence et al., 2015). Warfare also extends disruptions to manmade infrastructure which generally creates barriers to illnesses, including housing and sanitation and the access to medical care facilities that could prevent the spread of diseases. A variety of these factors could be taken advantage of in warfare, whether it be a passive allowance of weakening military strength in the face of soldiers' worsening living conditions, or the intentional spread of a pathogenic biological agent by natural vectors or artificial delivery systems. Like other major wartime diseases like Influenza and Typhoid Fever, hantaviruses have been identified in a variety of different conflicts.

Puumala virus causes a milder form of HFRS called Nephropathia Epidemica (NE) and is spread by the bank vole in Europe (Vapalahti et al., 2003). It is suspected that hantaviruses, specifically PUUV, spread across Europe during WWI in the form of Trench Nephritis which can be attributed to the congestion of soldiers and rodents in tight places, including trench lines that destroyed farmland and undermined infrastructure (Johnson, 2001; Schmaljohn, 2009; Lameire, 2014). Trench diseases, including Trench Foot, Trench Fever, and Trench Nephritis, constituted 25\% of the British Expeditionary Force's triage bed occupancy, and when the US entered the war in $1917,0.54 \%$ of their 370,000 military personnel were affected by NE (Lameire, 2014). HFRS and hantaviruses as a whole came to the attention of western medicine during the Korean War (1950-1953) which observed 3,200 United Nations troops becoming infected, with HTNV being isolated and identified as the etiological agent in 1978 (Gajdusek, 1962; Lee et al., 2004). Similarly, in the early 1930s, Soviet troops encountered a similar disease along the Amur River that caused nephritis, bleeding, and shock while Imperial Japanese forces suffered 12,000 cases as they invaded Manchuria during the Second Sino-Japanese War (19371945) (Schmaljohn, 2009; Lameire, 2014). Aside from the 1993 HCPS outbreak, major hantavirus outbreaks such as HTNV and PUUV are associated with war.

Consequently, the military is a natural target for hantavirus as a result of their activities occurring in largescale field exercises or in land-based combat which can disrupt natural habitats and cause exposure to hantaviruses by dispersing HCPS-causing rodents as was the case for HFRS-causing Apodemus agrarius or the striped field mouse (Clement et al., 1996). HCPS cases continue to be reported following military personnel encounters with the rodent reservoir, especially in large-scale military exercises that overlap with the rodent reservoirs habitats (Parkes et al., 2016). The congregation of soldiers in poorly ventilated or rarely maintained defenses such as trench lines or housing complexes are at risk to the infestation of HCPS-causing rodents regardless of SNV or ANDV's weaponization. As defenses and facilities decay overtime due to resource scarcity and war attrition, the ability to maintain sanitation and regular hygiene will be compromised enabling a return of Trench Nephritis and 
HCPS pulmonary disease. This can be further exacerbated by the influx and settling of refugees in consolidated camps which lack proper infrastructure and sanitation to prevent the spread of diseases let alone maintain barriers to hantavirus reservoir spread. This is evident by the influx of refugees generated from the conflict during the Yugoslav Wars (1991-2001) where civil unrest and internecine conflict caused massive movements of people and resulted in military and civilian exposure to hantaviruses, including the novel, HFRS-causing hantavirus DOBV which inflicted a 20\% mortality rate (Markotic et al., 1996; Bugert et al., 1999). Incidentally, as infrastructure decays or is undermined by war, more people will be exposed to debilitating hantaviruses as contact with rodent reservoirs increases.

Within the range of the military, it would be appropriate to develop strategies to delay or inundate military forces by exposure to hantavirus through natural infection models. This would observe HCPS-causing hantaviruses to be deployed as area denial weapons which are employed to slow the advance or endanger target militaries. Area denial weapons tend to restrict the momentum of target forces, usually forcing them into positions of vulnerability which may include adopting additional precautions to manage and mitigate the effects of the bioweapon itself. Employing New-World Hantaviruses in this respect, whether it be the physical dispersal of HCPSinfected rodents to undermine the entrenched living conditions of soldiers, or the deployment of aerosolized virion particles would significantly affect the morale, strength, and movement of the target army. A strategy of area denial would be to harbor HCPS-causing rodents in built-up areas to prevent the appropriation of urban infrastructure by an invading force. Abandoned facilities would be especially exceptional since SNV is found highly aerosolized in small, $\leq 1 \mu \mathrm{m}$ particulate matter that is far-more easily disturbed to the breathing zone $(1.5 \mathrm{~m}$ height) from walking rather than sweeping (Richardson et al., 2013). Soldiers seizing urban areas would be most vulnerable, especially during the spring and summer months where reservoir breeding and particulate aerosolization increases (Waltee et al., 2009). SNV may also persist in excreta for longer since sunlight and UV radiation are blocked from actively degrading the virions due to the protection vacant buildings provide (Douglass et al., 2006).

\section{Unconventional Warfare Settings and Civilian Targets}

Targets to a country's civilian populace or economic and industrial sectors are important alternatives for bioterrorist organizations or low-parity nations that cannot compete with modern industrial militaries. As illustrated by the 2019 SARS-CoV-2 pandemic, infectious diseases have the effect of compromising the entire socio-economic systems of countries and will be a practical target for most bioterrorist organizations. A bioweapons' attack will likely force the civilian populace to seek shelter or undergo rigorous quarantine measures which will affect the consumption of products from primary and secondary sectors of industry. The 2019 SARS-CoV-2 pandemic's quarantining especially reduced demand for oil and petroleum products, manufacturing, and agriculture worldwide as isolated civilians were no longer able to consume and grow the economy at previous rates resulting in a decline in overall national GDP (Nicola et al., 2020). Furthermore, impediments to the social fabric caused by the pandemic resulted in an overall abated pattern of life that observed closures of schools, increased hospitalization and pressures on the medical systems, as well as an increase in government debt and expenditure to maintain the stability of their financial sectors (Nicola et al., 2020). HCPS-causing Hantaviral bioweapons could be deployed in this way to afflict damage to a nation's industrial output or to invoke panic amongst a civilian populace which would affect a country's ability to fight conflicts abroad or domestically.

Farmers are naturally affected by the presence of hantaviruses due to their outdoor activities and cultivation of farmland which overlap rodent reservoir habitats (Vapalahti et al., 1999). A possible biothreat scenario involving hantavirus would likely target agriculture centers by increasing the incidence of contact with HCPS-causing rodents preventing farmers from working or by forcing them to require additional and costly protective equipment which would create delays in production. This includes traditional farmers utilizing lumber as a fuel source as firewood handling could result in the close contamination from Hantaviral infected aerosols or dust (Van Loock et al., 1999). The risk from storage or lumber shelters will especially affect those in the lumber and forestry industries and can thus be a target for a slow delivery in addition to an either targeted or widescale dispersal of hantavirus bioweapon which would delay or harass industrial production.

Hantaviruses, because of their global nature, have the capacity to affect infrastructure especially shipping and trade. Given a major outbreak, major ports contaminated with aerosolized hantaviruses have the capacity to create delays in trade which will endanger the economy of a target country. HFRS-causing SEOV is found worldwide because of its ubiquitous rodent reservoir the brown rat (Rattus norvegicus) whose close relationship with humans and subsequent dissemination through global trade, human migrations, and settlement has enabled its transit and viability (Lin et al., 2012). The presence of the brown rat in most major urban centers and in key transport industries such as maritime and land shipping can create a vulnerability to trade if targeted by bioterrorist organizations. Having a simple rodent infestation can threaten food stores and given hantaviruses general durability in moderate temperatures and low-UV light environments such as storage containers will allow aerosolized hantaviruses to survive up to 2-weeks and create hazards for government or civilian responders. Selective pressures and challenging environments like highlands, deserts, and cities will likely prevent dispersal of natural reservoirs of hantavirus such as deer mice. However, in North America, similar species to deer mice such as Peromyscus leucopus or the whitefooted mouse have occupied effective niches in cities on the east coast of Canada and the United States and have taken advantage of urban environment's lack of predators and natural competitors, its warmer climate for mating, and its abundance of small forest fragments for habitation (Munshi-South and Richardson, 2017). Attempting to build a natural reservoir in the city would take generations of rodent colonies and would itself 
be unviable given time, resources, and current rodent controls and proofing.

Hantaviruses also pose a risk to food consumption as well if improperly stored (Risteska-Nejashmikj et al., 2019; Wang et al., 2020). Hantaviruses, with PUUV and ANDV being studied, are not easily digested by stomach acids and can survive long enough to be passed into the gastrointestinal tract. Despite the requirements for intragastric route infection being the least effective, the oral route of infection is plausible for PUUV (Witkowski et al., 2017). Contaminating food and water supplies with biological weapons generally produces fewer casualties compared to an airborne release, but may be a secondary consequence resulting from a primary release (White, 2002). This would be the effect of having a warehouse contaminated with Hantaviral aerosols which will contaminate food stocks contained in tin cans or boxed containers. The consequence is two-fold. The first involves the vast stores of merchandise and material needing to undergo rigorous decontamination or disposal to prevent subsequent human contact and illness which will affect economic output. The second, if successful, will cause an indirect aerosol route of transmission to humans which could be widespread due to the nature of modern supply chains and distribution.

Hantaviruses are only currently pathogenic to humans as their rodent reservoirs remain chronically infected and asymptomatic of the disease, however, they continue to be highly viremic as the natural host produces antibodies including neutralizing antibodies (Netski et al., 1999; Ermonval et al., 2016). HFRS-causing hantaviruses are found to infect a wide array of rodents and insectivore species including bats, as well as hantavirus antibodies being found in domestic animals such as cats, dogs, rabbits, and pigs (Zhang et al., 2010). The infection of domestic animals and livestock such as cows is a concern because it produces another route of transmission between animals to humans. PUUV was demonstrated to experimentally infect bovine aortic endothelial cells, however, it is unknown whether asymptomatic persistent infections exist in domestic animals (Muranyi et al., 2004). Consequently, the effect on animals is fairly low as HCPS-causing hantaviruses do not cause disease in animals which remain largely asymptomatic (Krüger et al., 2011). This includes monkeys, with the only non-human primate exception being SNV-infected rhesus macaques and ANDV in Syrian hamsters which experienced severe HCPS-disease as a result of Vero E6 propagated virions (Hooper et al., 2001; Safronetz et al., 2014). Incidentally, targets for livestock and agriculture within bioterrorism attacks are very unlikely when using hantaviruses.

One of the limitations of hantaviruses is that they spread by specific rodent host species with most being spread by one or a few closely related rodents which reflect the co-evolutionary relationships hantaviruses generally have with their reservoirs (Hughes and Friedman, 2000). Hantavirus evolution and reassortment is limited to intraspecies reassortment and interlineage events within the same, single rodent reservoir (Klempa, 2018). Like Influenza, Hantaviruses are segmented and are able to undergo reassortment events with the exchange of gene segments between viruses that infect the same cells. The formation of antigenic shifts through reassortment events act as new ways for segmented viruses to adapt to new animal hosts and to increase infectivity. This can result in the formation of novel progeny viruses that are genetically distinct from the parental viruses and could be employed as the method of developing more pathogenic hantaviruses by bioterrorist organizations, especially with different HCPS-causing reservoir hosts co-located in close proximity (Klempa, 2018).

ANDV and SNV are genetically distinct hantaviruses that circulate in different regions and different rodent reservoirs. Despite ANDV not being maintained in deer mice, it can infect the SNV rodent reservoir allowing for new serotypes to occur (Ermonval et al., 2016). Additionally, ANDV and SNV reassortment events produced diploid and monoploid viruses with SNV S and L Segments and ANDV M Segments, which efficiently replicated in Vero E6 cells (Rizvanov et al., 2004). Infectivity of these new viruses takes on the characteristics of the ANDV M Segment they have adopted, and is suggested that reassortments of $M$ Segment substitutions promote virus survival by increasing its infectivity (Rizvanov et al., 2004). Previous in vitro studies have observed the mixing of distinct strains of SNV in Vero E6 cells generating new reassorted viruses (Rodriguez et al., 1998). Pathogenic SNV NMR11 strains were also able to reassort with nonpathogenic Black Creek Canal Virus (BCCV), a distantly related New-World Hantavirus that infects a different rodent species, the cotton rat (Sigmodon hispidus) (Rodriguez et al., 1998). Despite the low frequency of reassortment and the lack of predominance of any specific segment over the other, the ability for the strains to reassort highlights the importance reassortment as a genetic mechanism is in the emergence of new and possibly more lethal hantaviruses (Rodriguez et al., 1998).

Naturally occurring SNV reassortments are rather limited though and generally occur within local deer mouse populations just because of the local ecology supporting so few rodent species who rarely encounter each other and allow natural reassortment to occur. This is also undermined by the increasing genetic distance between rodent species that make reassortments less frequent (Henderson et al., 1995). However, bioterrorist organizations can artificially force these interactions by ensuring infected rodent species are grouped together with similar species like bats, voles, or shrews to enable the reassortment of pathogenic hantaviruses to form. This is similar to the case of a lethal genotype of ANDV, Araraquara orthohantavirus (ARQV) being documented in neotropical bats in Brazil which exposes the possibility of creating recombinant viruses with more infectious and morbid segmented negative-sense RNA pathogens such as Ebola Virus or Influenza-type viruses (Sabino-Santos et al., 2018). The threat of reassortment enables hantaviruses to develop new opportunities to host-switch. This is especially important since mixing $M$ Segments and their expressed glycoproteins enable the virus to interact with cell membrane proteins for entry, creating new routes of entry and new cell targets from old viruses (Klempa, 2018). Considering that reassortments can be done in vitro, the opportunity for bioengineering 
by random reassortments of pathogenic and non-pathogenic hantaviruses is possible.

\section{Transmission}

Compared to other hantaviruses like PUUV which readily transmits between bank voles and persists effectively within the environment, SNV retains some limitations to its transmission both horizontally between rodents and vertically to humans (Kallio et al., 2006). SNV horizontal transmission between its rodent reservoir has been observed to occur through biting and scratching, frequently among males with indirect transmission being possible among laboratory-inoculated rodents (Bagamian et al., 2012). Although transmission from contaminated excreta is possible, freshly infected deer mice were more likely to shed the virus and transmit it horizontally at the 14 days post-infection stage where SNV replication appeared the highest (Warner et al., 2019a). These recent studies of horizontal infection between deer mice discovered that SNV-infection only occurred in $24 \%$ of the uninfected deer mice caged with a same-sex SNV-infected mate for 6 weeks. Additionally, subsequent experiments accounting for long-term shedding noticed no further uninfected deer mice contracting SNV from uncleaned cages alone (Warner et al., 2019a). In contrast, ANDV transmitted more efficiently between uninfected cage mates whilst maintaining higher persistence in the environment (Padula et al., 2004). Additionally, reproductively active males with wounds comprised the majority of ANDV seropositive Oligoryzomys longicaudatus rodent members with horizontal transmission being primarily through male intersexual competition (Juan et al., 2019). This offers a way to increase transmission horizontally to amplify hantavirus presence in the environment but is itself a difficult and resource consuming method. Ultimately, the positive pressure of SNV infection horizontally is limited to direct and aggressive interactions within the reservoir which affects how quickly a reservoir can be infected and dispersed against a military target. This also affects the cultivation of Hantaviral virions for concentration as the viral replication is impeded by the slow infection rate between deer mice.

While all hantaviruses are spread to humans via the inhalation of contaminated dust and aerosols dispersed from rodent feces, urine, saliva, and fur, the viability of its spread is limited to peridomestic risk areas such as barns, cabins, or warehouses (Douglass et al., 2006; Lonner et al., 2008). The extent of SNV infection is thus restricted to the presence of deer mice as the main delivery system until the foundation of more effective passaging and isolation techniques arise to make artificial airborne dispersal techniques more effective.

Unlike SNV and other hantaviruses, ANDV has a distinguishable route of transmission because of its ability to spread person-to-person exemplified by several small cluster outbreaks in Southern Chile and Argentina (Toro et al., 1998; Martinez et al., 2005). For person-to-person transmission to occur, close contact is required which increases the risk to people living in the same household as well as sexual partners. The presence of ANDV in the alveolar epithelium and salivary glands of Sigmondontine rodents reinforces intraspecies transmission from saliva and biting (Padula et al., 2004).
ANDV infected patients have shown the virus to be present in pneumocytes and pulmonary macrophages, with ultrastructural and immunocytochemical studies revealing viral replication occurring in the alveolar epithelial cells with virus-like particles being released into the alveolar lumen (Pizarro et al., 2019). ANDV is likely secreted into human saliva and transmitted through close, intimate encounters or by exposure to respiratory droplets released through coughing or sneezing. There has also been reports of person-to-person transmission of ANDV from breast milk to new-borns, compounded by the new-borns' inadequate immune system and the presence of vRNA in the breast milk (Bellomo et al., 2020). Nevertheless, ANDV person-to-person transmission appears to be limited to close contacts and not nearly similar to the transmission rate and basic reproduction numbers $\left(\mathrm{R}_{\mathrm{O}}\right)$ of SARS-CoV-2 or Category A Pathogens such as Ebola Virus which have been assessed to be greater than 1 (Althaus, 2014; Park, 2020). ANDV's $R_{O}$ number has been estimated to be significantly less than 1 and would likely not initiate a pandemic within the parameters of the current data (Woolhouse et al., 2016). Incidentally, the risk, albeit present, is rather limited because the efficacy of ANDV being rapidly disseminated throughout a target group is dependent largely on aerosol inhalation or contact with contaminated saliva with the latter being an unpractical method to strike at large target populations.

\section{Dispersal and Delivery}

Since hantaviruses are transmitted to humans from rodents, a rudimentary but deliberate release of infected rodents into a target location would be a relatively easy way to threaten public health (Lõhmus et al., 2013). The impact would be low, but a strike against a country's key infrastructure like trade ports, warehouses, hospitals, governments centers, or public gatherings with infected rodents would create delays to productivity and the economy. Modern, industrialized countries in the west would not undergo famine or experience food insecurity as a result of a biological attack to the agriculture sector because of its robustness in diversity, high-production and heightened regulation (Wheelis et al., 2009). However, disruptions caused by the presence of suspected or confirmed biological agents has the potential to inflict market speculation and contraction through bans on international food exports resulting in lost revenue, job losses, and the destruction of capital including livestock or contaminated merchandise. This is indicated by the pig and cow culling during the Foot and Mouth Disease and the Bovine Spongiform Encephalopathy outbreaks in the United Kingdom, United States, and the Republic of China in 1997 and the early 2000s (Dudley and Woodford, 2002). The intent would be to cripple infrastructure and overburden the economy and medical apparatus. If introduced into a target rural or urban area, infected rodents have the potential to cause long-term medical incidents and create public panic that will have the effect of consuming municipal or federal resources required to manage the attack (Lõhmus et al., 2013). Additionally, retaining and cultivating deer mice for Hantaviral preparation is cost effective and commercially available. Deer mice are easily maintained following standard laboratory mouse protocols with deer mice 
being no different from lab mice in terms of handling with the exceptions of their aggressive tendencies involving biting and their agility resulting in escape which prompts increased biosafety measures to be taken (Joyner et al., 1998; Martin et al., 2016). Deer mice also suffer from not being genetically homogeneous resulting in inconsistency in experimentation due to widespread and significant genetic polymorphisms.

Rodent dispersal is discreet and innocuous, and can go unnoticed compared to bioweapons deployed by artillery, missiles, or by aerial deployment by aerosols. One limitation of Hantaviral deployment by artillery or missile is due to its $60^{\circ} \mathrm{C}$ heat sensitivity as any incendiary or kinetic deployment system would inactivate and degrade Hantaviral virions (White, 2002). The preferable deployment mechanism would be an aerosolization or powdered pathway which is undetectable and can achieve rapid dispersal over a wide area (White, 2002). Hantavirus delivery could benefit from similar dispersal methods employed to transport Anthrax or Ricin toxins such as letters and mailed packages due to their persistence in UV-free environments (Bhalla and Warheit, 2004). This becomes a problem since hantaviruses are undetectable in these delivery systems which urges for the development of new diagnostic and detection equipment. Hantavirus infections in humans are diagnosed with tedious enzyme-linked immunosorbent assay (ELISA), or IgM-capture tests to detect IgM antibodies and also RT-PCR detection of viral RNA in rodent or insectivore hosts (Vaheri et al., 2008). However, the limitation of hantavirus isolation would prevent it from being assembled into an effective aerosol which would require high Hantaviral concentrations. This would require substantial laboratory resources and technical expertise to maintain sufficient viral stocks for weaponization, and would prove to be the leading difficulty for uninitiated bioterrorist organizations in accomplishing. Additionally, aerosols dispersed outside during the day have the risk of being degraded by the viricidal properties of UV radiation which poses another limitation to outdoor dispersal (Kraus et al., 2005). The optimal route would be to have dispersal mechanisms deploy indoors to prevent the seizure of facilities by militaries or to create disruptions for civilian personnel employed in key industrial sectors.

There does exist substantial methods of rodent and pest controls that target deer mice through bait and trappings, structural proofing and rodenticides which have proven both economical and effective in preventing rodent entry to structures including underdeveloped residences (Glass et al., 1997; Hopkins et al., 2002; Baldwin et al., 2014). By culling or isolating rodents through said techniques, rodent controls help to minimize human-rodent contact and ultimately transmission. This is exemplified by other rodent-borne Bunyaviruses such as the Arenavirus Lassa Virus which experienced a reduction in seroprevalence proportional to reductions in its North-West African reservoirs (Mastomys natalensis, Mastomys erythroleucus, Hylomyscus pamfi) through the use of rodenticides and urban proofing that targeted rodent and human food stocks and housing (Mari Saez et al., 2018). However, complete seroprevalence reduction of Lassa Virus relied upon an $80 \%$ reduction in rodent population densities indoors and in peridomestic environments to avoid lateral viral transmission which becomes labor and resource intensive and may not be feasible in developing countries or those affected by war (Mariën et al., 2019). Nevertheless, deployment of rodent hosts as physical carriers of a hantavirus bioweapon would be seriously hampered by a proactive application of bait poisons, fumigant poisons, or non-poisonous measures including traps. However, handling of caught rodents through traps including diseased rodents is both labor intensive and increases the risks associated with hantavirus exposure (Meerburg et al., 2008).

ANDV virus would be the preferred model for dispersal if conducting a specific one-target attack with collateral to personnel within an immediate vicinity. This is because ANDV can occur within household person-to-person contact and can cause up to $25-35 \%$ mortality rates (Krüger et al., 2011). An attack on a single target with the intent of causing panic and successive but limited infections within a household would be an unideal although possible diversionary method for assassination. Household contacts of ANDV are at risk of developing HCPS infections within 4 weeks with ANDV vRNA being routinely detected in blood cells for up to 2 weeks before symptoms or antihantavirus antibodies arise (Ferres et al., 2007). This enables a person-to-person model to be employed for targets that require discretion since infection can take effect weeks after the attempt has been made compared to overt assassination or sabotage attempts which risk immediate suspicion and association. This also enables the virus to be spread asymptomatically within an infected group, although an influenza-like pandemic seems unfeasible due to the strict requirements of ANDV infection relying on person-to-person contact being very close (Krüger et al., 2011).

\section{CONCLUSION}

With the limitations present, HCPS-causing hantaviruses are generally restricted to the Category $\mathrm{C}$ definition largely because their spread and ability to be concentrated in the laboratory faces difficult barriers. The feasibility of developing HCPScausing bioweapons comes from the few strengths hantaviruses possess which includes its high mortality rate. Hantaviruses can also be easily dispersed through aerosols if limited to indoor facilities or warehouses with no insolation and can effectively target personnel - especially the military - operating in close proximity to rodent reservoir habitats. HCPS-causing hantaviruses also benefit from being difficult to treat since no Old-World Hantavirus antivirals or vaccines have effective specificity against them. However, the morbidity rate of NewWorld Hantaviruses is very low, with ANDV being a potential but somewhat viable agent because of its person-to-person transmission pathway which would likely infect more people. Additionally, the ability to manufacture and produce ANDV or SNV into a lethal form that can be dispersed poses a problem to its weaponization due to the presence of attenuating mutations and absence of a strong disease model for non-human primates. Although widespread, the ability for HCPS-causing hantavirus reservoirs to adopt new urban environments is limited but may 
be improved by the effects of climate change and the increase in human industrial activity. As technologies improve and barriers to passaging and replicating hantavirus virions in culture become easier and more viable, the ability to mass-produce pathogenic HCPS-causing hantaviruses like SNV or ANDV may upgrade hantaviruses from a Category $\mathrm{C}$ to A definition.

Nevertheless, despite being a Category $C$ pathogen, the threat of hantaviruses infections generally and the potential for it to be weaponized should not be ignored. Hantaviruses are emerging pathogens that require the attention of government and medical health research as globally they still occur frequently in developing countries with poor infrastructure or in rural, agrarian environments that have close contact with Hantaviral rodent-reservoirs. Hantavirus and HCPS continue to be a serious pathogen and disease to be considered carefully due to the environmental-associated risks of frequent rodenthuman contact that expose military personnel, farmers and agriculture workers, and warehouse and shipping staff to the virus. The paucity of reporting in developing countries and the neglect that hantaviruses face allows it to slip under the radar and can be exploited by organizations that could potentially field extensive laboratory equipment and rodent reservoirs toward the development of hantavirus-based biological weapons. Infectious diseases generally can be mitigated with better reporting and surveillance, especially by monitoring the incidence of disease through extensive international health and medical networks. This can be accomplished by governments and academic agencies resolving to be proactive in testing, freely sharing clinical and experimental details, and maintaining intergovernmental transparency with regard to pandemics or the occurrence of bioweapon threats (Arthur et al., 2006). Naturally, with a stronger observation and tracking of infectious diseases the easier it is to identify and manage them when they occur.

Globally, the ability to employ biological agents is prohibited by the Biological and Toxin Weapon Convention (BTWC) ratified by the United Nations and 170 of their member states which has limited international biological warfare. However, because of their lack of inspection mechanisms, rogue states and terrorist organizations could circumvent the BTWC treaty and employ biological weapons against target nations (Jansen et al., 2014). The intent may not be to singly destroy a nation or completely kill its people, with terrorist objectives being more nuanced and complex such as the case with AlQaeda attempting to destabilize and disrupt US power in

\section{REFERENCES}

Alonso, D. O., Iglesias, A., Coelho, R., Periolo, N., Bruno, A., Cordoba, M. T., et al. (2019). Epidemiological description, case-fatality rate, and trends of Hantavirus Pulmonary Syndrome: 9 years of surveillance in Argentina. J. Med. Virol. 91, 1173-1181. doi: 10.1002/jmv.25446

Alonso, D. O., Perez-Sautu, U., Bellomo, C. M., Prieto, K., Iglesias, A., Coelho, R., et al. (2020). Person-to-person transmission of andes virus in hantavirus pulmonary syndrome, Argentina, 2014. Emerg. Infect. Dis. 26, 756-759. doi: 10.3201/eid2604.190799

Althaus, C. L. (2014). Estimating the Reproduction Number of Ebola Virus (EBOV) During the 2014 Outbreak in West Africa. PLoS the Middle-East (Keeney and Von Winterfeldt, 2010). Instead, the importance of disruption is key since any bioterror attack regardless of its category could inflict damage to a nation's populace, economy, and prestige which have deeper ramifications to global security. Consequently, further research into weaponization and surveillance are essential to prevent or mitigate the effects of bioweapons.

As a consideration, significant international and national cooperation must occur to safeguard global trade, public health, and international security from bioterrorism. Mitigation strategies against bioagent attacks can only be effective given the invested interests of governments and research scientists in protecting the health of their peoples. Incidentally, research into medical health science must be focused on building toward detection, identification, mitigation and management equipment and techniques with the concentration of resources from cooperating governments to fund developments in counterterrorism and medical therapeutics. This would require an intergovernmental exchange of communication between research scientists, policy-makers, and the public to broaden transparency toward international security and scientific research (Zhao et al., 2020). Through cooperation, predictions of future attacks or employment of bioagents can be ascertained, preventing socioeconomic collapses that could occur from industry-paralyzing infectious diseases.

\section{AUTHOR CONTRIBUTIONS}

MD'S and TP: conceptualization, formal analysis, writing, and visualization. TP: supervision and funding acquisition. Both authors read and agreed to the published version of the manuscript.

\section{FUNDING}

We thank Canada Research Chair program.

\section{ACKNOWLEDGMENTS}

TP acknowledges Canada Research Chair Program. Hantavirus Structure and Lifecycle Figures were prepared by Tyler Lieberthal (darkbloom) as a commercial service.

Curr. 6:ecurrents.outbreaks.91afb5e0f279e7f29e7056095255b288. doi: 10.1371/currents.outbreaks.91afb5e0f279e7f29e7056095255b288

Amroun, A., Priet, S., de Lamballerie, X., and Querat, G. (2017). Bunyaviridae RdRps: structure, motifs, and RNA synthesis machinery. Crit. Rev. Microbiol. 43, 753-778. doi: 10.1080/1040841x.2017.1307805

Arthur, R. R., Leduc, J. W., and Hughes, J. M. (2006). Surveillance for emerging infectious diseases and bioterrorism threats. Trop. Infect. Dis. 2006, 195-200.

Astorga, F., Escobar, L. E., Poo-Munoz, D., Escobar-Dodero, J., Rojas-Hucks, S., Alvarado-Rybak, M., et al. (2018). Distributional ecology of Andes hantavirus: a macroecological approach. Int. J. Health Geogr. 17:22.

Avsic-Zupanc, T., Saksida, A., and Korva, M. (2019). Hantavirus infections. Clin. Microbiol. Infect. 21s, e6-e16. 
Bagamian, K. H., Towner, J. S., Kuenzi, A. J., Douglass, R. J., Rollin, P. E., Waller, L. A., et al. (2012). Transmission ecology of Sin Nombre hantavirus in naturally infected North American deermouse populations in outdoor enclosures. PLoS One 7:e47731. doi: 10.1371/journal.pone.0047731

Baldwin, R. A., Quinn, N., Davis, D. H., and Engeman, R. M. (2014). Effectiveness of rodenticides for managing invasive roof rats and native deer mice in orchards. Environ. Sci. Pollut. Res. Int. 21, 5795-5802. doi: 10.1007/s11356014-2525-4

Bellomo, C., Alonso, D., Coelho, R., Iglesias, A., Periolo, N., and Martínez, V. P. (2020). A newborn infected by Andes virus suggests novel routes of hantavirus transmission: a case report. Clin. Microbiol. Infect. 26, 130-131. doi: 10.1016/j. cmi.2019.09.012

Beltran-Ortiz, C. E., Starck-Mendez, M. F., Fernandez, Y., Farnos, O., Gonzalez, E. E., Rivas, C. I., et al. (2017). Expression and purification of the surface proteins from Andes virus. Protein Expr. Purif. 139, 63-70. doi: 10.1016/j.pep. 2015.09.013

Benjamin, R., Berges, B. K., Solis-Leal, A., Igbinedion, O., Strong, C. L., and Schiller, M. R. (2016). TALEN gene editing takes aim on HIV. Hum. Genet. 135, 1059-1070. doi: 10.1007/s00439-016-1678-2

Berl, J. L., Kuenzi, A. J., Flaherty, E. A., and Swihart, R. K. (2018). Interspecific comparison of hantavirus prevalence in peromyscus populations from a fragmented agro-ecosystem in Indiana, USA. J. Wildl. Dis. 54, 147-150.

Bhalla, D. K., and Warheit, D. B. (2004). Biological agents with potential for misuse: a historical perspective and defensive measures. Toxicol. Appl. Pharmacol. 199, 71-84. doi: 10.1016/j.taap.2004.03.009

Borges, A. A., Campos, G. M., Moreli, M. L., Souza, R. L., Aquino, V. H., Saggioro, F. P., et al. (2006). Hantavirus cardiopulmonary syndrome: immune response and pathogenesis. Microbes Infect. 8, 2324-2330. doi: 10.1016/j.micinf.2006.04. 019

Brocato, R. L., Hammerbeck, C. D., Bell, T. M., Wells, J. B., Queen, L. A., and Hooper, J. W. (2014). A lethal disease model for hantavirus pulmonary syndrome in immunosuppressed Syrian hamsters infected with Sin Nombre virus. J. Virol. 88, 811-819. doi: 10.1128/jvi.02906-13

Brocato, R. L., and Hooper, J. W. (2019). Progress on the prevention and treatment of Hantavirus disease. Viruses 11:610. doi: 10.3390/v11070610

Brown, B. A., and Panganiban, A. T. (2010). Identification of a region of hantavirus nucleocapsid protein required for RNA chaperone activity. RNA Biol. 7, 830837. doi: 10.4161/rna.7.6.13862

Bugert, J. J., Welzel, T. M., Zeier, M., and Darai, G. (1999). Hantavirus infectionhaemorrhagic fever in the Balkans-potential nephrological hazards in the Kosovo war. Nephrol. Dial. Transplant. 14, 1843-1844. doi: 10.1093/ndt/14. 8.1843

CDC (2018). Bioterrorism Agents/Diseases. Available online at: https://emergency. cdc.gov/agent/agentlist-category.asp (accessed March 30, 2020).

Chapman, L. E., Mertz, G. J., Peters, C. J., Jolson, H. M., Khan, A. S., Ksiazek, T. G., et al. (1999). Intravenous ribavirin for hantavirus pulmonary syndrome: safety and tolerance during 1 year of open-label experience. Ribavirin Study Group. Antivir. Ther. 4, 211-219.

Cheng, E., Wang, Z., and Mir, M. A. (2014). Interaction between hantavirus nucleocapsid protein $(\mathrm{N})$ and RNA-dependent RNA polymerase (RdRp) mutants reveals the requirement of an N-RdRp interaction for viral RNA synthesis. J. Virol. 88, 8706-8712. doi: 10.1128/jvi.00405-14

Chiang, C. F., Flint, M., Lin, J. S., and Spiropoulou, C. F. (2016). Endocytic pathways used by Andes virus to enter primary human lung endothelial cells. PLoS One 11:e0164768. doi: 10.1371/journal.pone.0164768

Chizhikov, V. E., Spiropoulou, C. F., Morzunov, S. P., Monroe, M. C., Peters, C. J., and Nichol, S. T. (1995). Complete genetic characterization and analysis of isolation of Sin Nombre virus. J. Virol. 69, 8132-8136. doi: 10.1128/jvi.69.12. 8132-8136.1995

Cho, H. W., and Howard, C. R. (1999). Antibody responses in humans to an inactivated hantavirus vaccine (Hantavax). Vaccine 17, 2569-2575. doi: 10. 1016/s0264-410x(99)00057-2

Choi, Y., Ahn, C. J., Seong, K. M., Jung, M. Y., and Ahn, B. Y. (2003). Inactivated Hantaan virus vaccine derived from suspension culture of Vero cells. Vaccine 21, 1867-1873. doi: 10.1016/s0264-410x(03)00005-7

Christian, M. D. (2013). Biowarfare and Bioterrorism. Crit. Care Clin. 29, 717-756. doi: 10.1016/j.ccc.2013.03.015
Cimica, V., Dalrymple, N. A., Roth, E., Nasonov, A., and Mackow, E. R. (2014). An innate immunity-regulating virulence determinant is uniquely encoded by the Andes virus nucleocapsid protein. mBio 5:e01088-13.

Clement, J., Underwood, P., Ward, D., Pilaski, J., and LeDuc, J. (1996). Hantavirus outbreak during military manoeuvres in Germany. Lancet 347, 336. doi: 10. 1016/s0140-6736(96)90519-x

Clement, J. P. (2003). Hantavirus. Antiviral Res. 57, 121-127.

Connolly-Andersen, A. M., Sundberg, E., Ahlm, C., Hultdin, J., Baudin, M., Larsson, J., et al. (2015). Increased Thrombopoiesis and Platelet Activation in Hantavirus-Infected Patients. J. Infect. Dis. 212, 1061-1069. doi: 10.1093/infdis/ jiv161

Connolly-Andersen, A. M., Thunberg, T., and Ahlm, C. (2014). Endothelial activation and repair during hantavirus infection: association with disease outcome. Open Forum Infect. Dis. 1:ofu027.

de St Maurice, A., Ervin, E., Schumacher, M., Yaglom, H., VinHatton, E., Melman, S., et al. (2017). Exposure characteristics of hantavirus pulmonary syndrome patients, United States, 1993-2015. Emerg. Infect. Dis. 23, 733-739. doi: 10. 3201/eid2305.161770

Doganay, M., and Demiraslan, H. (2015). Human anthrax as a re-emerging disease. Recent Pat. Antiinfect. Drug Discov. 10, 10-29. doi: 10.2174/ 1574891x10666150408162354

Douglass, R. J., Semmens, W. J., Matlock-Cooley, S. J., and Kuenzi, A. J. (2006). Deer mouse movements in peridomestic and sylvan settings in relation to Sin Nombre virus antibody prevalence. J. Wildl. Dis. 42, 813-818. doi: 10.7589/ 0090-3558-42.4.813

Drebot, M. A., Jones, S., Grolla, A., Safronetz, D., Strong, J. E., Kobinger, G., et al. (2015). Hantavirus pulmonary syndrome in Canada: an overview of clinical features, diagnostics, epidemiology and prevention. Can. Commun. Dis. Rep. 41, 124-131. doi: 10.14745/ccdr.v41i06a02

Dudley, J. P., and Woodford, M. H. (2002). Bioweapons, bioterrorism and biodiversity: potential impacts of biological weapons attacks on agricultural and biological diversity. Rev. Sci. Tech. 21, 125-137. doi: 10.20506/rst.21.1. 1328

Duehr, J., McMahon, M., Williamson, B., Amanat, F., Durbin, A., Hawman, D. W., et al. (2020). Neutralizing monoclonal antibodies against the Gn and the Gc of the Andes virus glycoprotein spike complex protect from virus challenge in a preclinical hamster model. mBio 11:e00028-20.

Eckerle, I., Lenk, M., and Ulrich, R. G. (2014). More novel hantaviruses and diversifying reservoir hosts-time for development of reservoir-derived cell culture models? Viruses 6, 951-967. doi: 10.3390/v6030951

Elliott, L. H., Ksiazek, T. G., Rollin, P. E., Spiropoulou, C. F., Morzunov, S., Monroe, M., et al. (1994). Isolation of the causative agent of hantavirus pulmonary syndrome. Am. J. Trop. Med. Hyg. 51, 102-108.

Emeny, J. M., and Morgan, M. J. (1979). Regulation of the interferon system: evidence that Vero cells have a genetic defect in interferon production. J. Gen. Virol. 43, 247-252. doi: 10.1099/0022-1317-43-1-247

Engelthaler, D. M., Mosley, D. G., Cheek, J. E., Levy, C. E., Komatsu, K. K., Ettestad, P., et al. (1999). Climatic and environmental patterns associated with hantavirus pulmonary syndrome, Four Corners region, United States. Emerg. Infect. Dis. 5, 87-94. doi: 10.3201/eid0501.990110

Ermonval, M., Baychelier, F., and Tordo, N. (2016). What do we know about how Hantaviruses interact with their different hosts? Viruses 8:223. doi: 10.3390/ v8080223

Escalera-Antezana, J. P., Torrez-Fernandez, R., Montalvan-Plata, D., MontenegroNarvaez, C. M., Aviles-Sarmiento, J. L., and Alvarado-Arnez, L. E. (2020). Orthohantavirus pulmonary syndrome in Santa Cruz and Tarija, Bolivia, 2018. Int. J. Infect. Dis. 90, 145-150. doi: 10.1016/j.ijid.2019.10.021

Ferres, M., Vial, P., Marco, C., Yanez, L., Godoy, P., Castillo, C., et al. (2007). Prospective evaluation of household contacts of persons with hantavirus cardiopulmonary syndrome in chile. J. Infect. Dis. 195, 1563-1571. doi: 10. $1086 / 516786$

Figueiredo, L. T., Souza, W. M., Ferres, M., and Enria, D. A. (2014). Hantaviruses and cardiopulmonary syndrome in South America. Virus Res. 187, 43-54. doi: 10.1016/j.virusres.2014.01.015

Fonseca, L. X., Oliveira, S. V., and Duarte, E. C. (2018). Magnitude and distribution of deaths due to hantavirus in Brazil, 2007-2015. Epidemiol. Serv. Saude 27:e2017221. 
Forbes, K. M., Sironen, T., and Plyusnin, A. (2018). Hantavirus maintenance and transmission in reservoir host populations. Curr. Opin. Virol. 28, 1-6. doi: 10.1016/j.coviro.2017.09.003

Fulhorst, C. F., Monroe, M. C., Salas, R. A., Duno, G., Utrera, A., and Ksiazek, T. G. (1997). Isolation, characterization and geographic distribution of Caño Delgadito virus, a newly discovered South American hantavirus (family Bunyaviridae). Virus Res. 51, 159-171.

Gajdusek, D. C. (1962). Virus hemorrhagic fevers. Special reference to hemorrhagic fever with renal syndrome (epidemic hemorrhagic fever). J. Pediatr. 60, 841857.

Galeno, H., Mora, J., Villagra, E., Fernandez, J., Hernandez, J., Mertz, G. J., et al. (2002). First human isolate of Hantavirus (Andes virus) in the Americas. Emerg. Infect. Dis. 8, 657-661. doi: 10.3201/eid0807.010277

Garcin, D., Lezzi, M., Dobbs, M., Elliott, R. M., Schmaljohn, C., Kang, C. Y., et al. (1995). The $5^{\prime}$ ends of Hantaan virus (Bunyaviridae) RNAs suggest a prime-andrealign mechanism for the initiation of RNA synthesis. J. Virol. 69, 5754-5762. doi: 10.1128/jvi.69.9.5754-5762.1995

Gavrilovskaya, I. N., Brown, E. J., Ginsberg, M. H., and Mackow, E. R. (1999). Cellular entry of hantaviruses which cause hemorrhagic fever with renal syndrome is mediated by beta3 integrins. J. Virol. 73, 3951-3959. doi: 10.1128/ jvi.73.5.3951-3959.1999

Gavrilovskaya, I. N., Shepley, M., Shaw, R., Ginsberg, M. H., and Mackow, E. R. (1998). beta3 Integrins mediate the cellular entry of hantaviruses that cause respiratory failure. Proc. Natl. Acad. Sci. U.S.A. 95, 7074-7079. doi: 10.1073/ pnas.95.12.7074

Glass, G. E., Johnson, J. S., Hodenbach, G. A., Disalvo, C. L., Peters, C. J., Childs, J. E., et al. (1997). Experimental evaluation of rodent exclusion methods to reduce hantavirus transmission to humans in rural housing. Am. J. Trop. Med. Hyg. 56, 359-364. doi: 10.4269/ajtmh.1997.56.359

Godoy, P., Marsac, D., Stefas, E., Ferrer, P., Tischler, N. D., Pino, K., et al. (2009). Andes virus antigens are shed in urine of patients with acute hantavirus cardiopulmonary syndrome. J. Virol. 83, 5046-5055. doi: 10.1128/jvi. 02409-08

Goeijenbier, M., Aron, G., Anfasa, F., Lundkvist, A., Verner-Carlsson, J., and Reusken, C. B. (2015). Emerging Viruses in the Republic of Suriname: retrospective and prospective study into Chikungunya Circulation and Suspicion of Human Hantavirus Infections, 2008-2012 and 2014. Vector Borne Zoonotic Dis.15, 611-618. doi: 10.1089/vbz.2015.1798

Goldsmith, C. S., Elliott, L. H., Peters, C. J., and Zaki, S. R. (1995). Ultrastructural characteristics of Sin Nombre virus, causative agent of hantavirus pulmonary syndrome. Arch. Virol. 140, 2107-2122. doi: 10.1007/bf01323234

Gubler, D. J., Reiter, P., Ebi, K. L., Yap, W., Nasci, R., and Patz, J. A. (2001). Climate variability and change in the United States: potential impacts on vectorand rodent-borne diseases. Environ. Health Perspect. 109(Suppl. 2), 223-233. doi: 10.1289/ehp.109-1240669

Guterres, A., and de Lemos, E. R. S. (2018). Hantaviruses and a neglected environmental determinant. One Health 5, 27-33. doi: 10.1016/j.onehlt.2017. 12.002

Hardestam, J., Simon, M., Hedlund, K. O., Vaheri, A., Klingstrom, J., and Lundkvist, A. (2007). Ex vivo stability of the rodent-borne Hantaan virus in comparison to that of arthropod-borne members of the Bunyaviridae family. Appl. Environ. Microbiol. 73, 2547-2551. doi: 10.1128/aem.02869-06

Hartline, J., Mierek, C., Knutson, T., and Kang, C. (2013). Hantavirus infection in North America: a clinical review. Am. J. Emerg. Med. 31, 978-982. doi: 10.1016/j.ajem.2013.02.001

Henderson, W. W., Monroe, M. C., St Jeor, S. C., Thayer, W. P., Rowe, J. E., Peters, C. J., et al. (1995). Naturally occurring Sin Nombre virus genetic reassortants. Virology 214, 602-610. doi: 10.1006/viro.1995.0071

Hepojoki, J., Strandin, T., Lankinen, H., and Vaheri, A. (2012). Hantavirus structure-molecular interactions behind the scene. J. Gen. Virol. 93(Pt 8), 1631-1644. doi: 10.1099/vir.0.042218-0

Higa, M. M., Petersen, J., Hooper, J., and Doms, R. W. (2012). Efficient production of Hantaan and Puumala pseudovirions for viral tropism and neutralization studies. Virology 423, 134-142. doi: 10.1016/j.virol.2011.08.012

Hjelle, B., Jenison, S., Mertz, G., Koster, F., and Foucar, K. (1994). Emergence of hantaviral disease in the southwestern United States. West. J. Med. 161, $467-473$.
Hooper, J. W., Larsen, T., Custer, D. M., and Schmaljohn, C. S. (2001). A lethal disease model for hantavirus pulmonary syndrome. Virology 289, 6-14. doi: 10.1006/viro.2001.1133

Hopkins, A. S., Whitetail-Eagle, J., Corneli, A. L., Person, B., Ettestad, P. J., DiMenna, M., et al. (2002). Experimental evaluation of rodent exclusion methods to reduce hantavirus transmission to residents in a Native American community in New Mexico. Vector Borne Zoonotic Dis. 2, 61-68. doi: 10.1089/ 153036602321131850

Hughes, A. L., and Friedman, R. (2000). Evolutionary diversification of proteincoding genes of hantaviruses. Mol. Biol. Evol. 17, 1558-1568. doi: 10.1093/ oxfordjournals.molbev.a026254

Hussein, I. T., Haseeb, A., Haque, A., and Mir, M. A. (2011). Recent advances in hantavirus molecular biology and disease. Adv. Appl. Microbiol. 74, 35-75. doi: 10.1016/b978-0-12-387022-3.00006-9

Hutchinson, K. L., Peters, C. J., and Nichol, S. T. (1996). Sin Nombre virus mRNA synthesis. Virology 224, 139-149. doi: 10.1006/viro.1996.0515

Iannetta, M., Di Caro, A., Nicastri, E., Vairo, F., Masanja, H., Kobinger, G., et al. (2019). Viral Hemorrhagic Fevers Other than Ebola and Lassa. Infect. Dis. Clin. North Am. 33, 977-1002. doi: 10.1016/j.idc.2019.08.003

Jansen, H. J., Breeveld, F. J., Stijnis, C., and Grobusch, M. P. (2014). Biological warfare, bioterrorism, and biocrime. Clin. Microbiol. Infect. 20, 488-496. doi: 10.1111/1469-0691.12699

Jiang, H., Zheng, X., Wang, L., Du, H., Wang, P., and Bai, X. (2017). Hantavirus infection: a global zoonotic challenge. Virol. Sin. 32, 32-43. doi: 10.1007/ s12250-016-3899-x

Jin, M., Park, J., Lee, S., Park, B., Shin, J., Song, K. J., et al. (2002). Hantaan virus enters cells by clathrin-dependent receptor-mediated endocytosis. Virology 294, 60-69. doi: 10.1006/viro.2001.1303

Johnson, K. M. (2001). Hantaviruses: history and overview. Curr. Top. Microbiol. Immunol. 256, 1-14. doi: 10.1007/978-3-642-56753-7_1

Jonsson, C. B., Figueiredo, L. T., and Vapalahti, O. (2010). A global perspective on hantavirus ecology, epidemiology, and disease. Clin. Microbiol. Rev. 23, 412-441. doi: 10.1128/cmr.00062-09

Jonsson, C. B., Hooper, J., and Mertz, G. (2008). Treatment of hantavirus pulmonary syndrome. Antiviral Res. 78, 162-169.

Jonsson, C. B., and Schmaljohn, C. S. (2001). Replication of hantaviruses. Curr. Top. Microbiol. Immunol. 256, 15-32. doi: 10.1007/978-3-642-56753-7_2

Joyner, C. P., Myrick, L. C., Crossland, J. P., and Dawson, W. D. (1998). deer mice as laboratory animals. ILAR J. 39, 322-330. doi: 10.1093/ilar.39.4.322

Juan, E., Levis, S., Pini, N., Polop, J., Steinmann, A. R., and Provensal, M. C. (2019). Mechanisms of hantavirus transmission in Oligoryzomys longicaudatus. Ecohealth 16, 671-681. doi: 10.1007/s10393-019-01454-y

Kallio, E. R., Klingstrom, J., Gustafsson, E., Manni, T., Vaheri, A., Henttonen, H., et al. (2006). Prolonged survival of Puumala hantavirus outside the host: evidence for indirect transmission via the environment. J. Gen. Virol. 87(Pt 8), 2127-2134. doi: 10.1099/vir.0.81643-0

Kamrud, K. I., and Schmaljohn, C. S. (1994). Expression strategy of the M genome segment of Hantaan virus. Virus Res. 31, 109-121. doi: 10.1016/0168-1702(94) 90074-4

Kariwa, H., Fujiki, M., Yoshimatsu, K., Arikawa, J., Takashima, I., and Hashimoto, N. (1998). Urine-associated horizontal transmission of Seoul virus among rats. Arch. Virol. 143, 365-374. doi: 10.1007/s007050050292

Kato, H., Takeuchi, O., Sato, S., Yoneyama, M., Yamamoto, M., Matsui, K., et al. (2006). Differential roles of MDA5 and RIG-I helicases in the recognition of RNA viruses. Nature 441, 101-105. doi: 10.1038/nature04734

Kawai, T., and Akira, S. (2007). TLR signaling. Semin. Immunol. 19, 24-32.

Keeney, G. L., and Von Winterfeldt, D. (2010). Identifying and structuring the objectives of terrorists. Risk Anal. 30, 1803-1816. doi: 10.1111/j.1539-6924. 2010.01472.x

Klempa, B. (2009). Hantaviruses and climate change. Clin. Microbiol. Infect. 15, 518-523. doi: 10.1111/j.1469-0691.2009.02848.x

Klempa, B. (2018). Reassortment events in the evolution of hantaviruses. Virus Genes 54, 638-646. doi: 10.1007/s11262-018-1590-z

Klingström, J., Plyusnin, A., Vaheri, A., and Lundkvist, A. (2002). Wild-type Puumala hantavirus infection induces cytokines, C-reactive protein, creatinine, and nitric oxide in cynomolgus macaques. J. Virol. 76, 444-449. doi: 10.1128/ jvi.76.1.444-449.2002 
Knust, B., and Rollin, P. E. (2013). Twenty-year summary of surveillance for human hantavirus infections, United States. Emerg. Infect. Dis. 19, 1934-1937. doi: 10.3201/eid1912.131217

Kraus, A. A., Priemer, C., Heider, H., Kruger, D. H., and Ulrich, R. (2005). Inactivation of Hantaan virus-containing samples for subsequent investigations outside biosafety level 3 facilities. Intervirology 48, 255-261. doi: 10.1159/ 000084603

Kruger, D. H., Schonrich, G., and Klempa, B. (2011). Human pathogenic hantaviruses and prevention of infection. Hum. Vaccin. 7, 685-693. doi: 10. 4161/hv.7.6.15197

Krüger, D. H., Schönrich, G., and Klempa, B. (2011). Human pathogenic hantaviruses and prevention of infection. Hum Vaccin 7, 685-693. doi: 10.4161/ hv.7.6.15197

Kukkonen, S. K., Vaheri, A., and Plyusnin, A. (2005). L protein, the RNAdependent RNA polymerase of hantaviruses. Arch. Virol. 150, 533-556. doi: 10.1007/s00705-004-0414-8

Lameire, N. (2014). Wars, disasters and kidneys. Acta Clin. Belg. 69, 418-425. doi: $10.1179 / 0001551214 z .00000000087$

Lawrence, M., Stemberger, H., Zolderdo, A., Struthers, D., and Cooke, S. (2015). The effects of modern war and military activities on biodiversity and the environment. Environ. Rev. 23, 443-460. doi: 10.1139/er-2015-0039

Lee, H. W., Lee, P. W., and Johnson, K. M. (2004). Isolation of the etiologic agent of Korean hemorrhagic fever. 1978. J. Infect. Dis. 190, 1711-1721. doi: 10.1093/infdis/190.9.1711

Levine, J. R., Prescott, J., Brown, K. S., Best, S. M., Ebihara, H., and Feldmann, H. (2010). Antagonism of type I interferon responses by new world hantaviruses. J. Virol. 84, 11790-11801. doi: 10.1128/jvi.00916-10

Li, J. L., Ling, J. X., Chen, L. J., Wei, F., Luo, F., Liu, Y. Y., et al. (2013). An efficient method for isolation of Hantaan virus through serial passages in suckling mice. Intervirology 56, 172-177. doi: 10.1159/000345444

Li, N., Luo, F., Chen, Q., Zhu, N., Wang, H., Xie, L., et al. (2019). IFN- $\lambda$ s inhibit Hantaan virus infection through the JAK-STAT pathway and expression of Mx2 protein. Genes Immun. 20, 234-244. doi: 10.1038/s41435-018-0028-x

Lin, X. D., Guo, W. P., Wang, W., Zou, Y., Hao, Z. Y., Zhou, D. J., et al. (2012). Migration of Norway rats resulted in the worldwide distribution of Seoul hantavirus today. J. Virol. 86, 972-981. doi: 10.1128/jvi.00725-11

Liu, R., Ma, H., Shu, J., Zhang, Q., Han, M., Liu, Z., et al. (2019). Vaccines and therapeutics against Hantaviruses. Front. Microbiol. 10:2989. doi: 10.3389/ fmicb.2019.02989

Llah, S. T., Mir, S., Sharif, S., Khan, S., and Mir, M. A. (2018). Hantavirus induced cardiopulmonary syndrome: a public health concern. J. Med. Virol. 90, 1003-1009. doi: 10.1002/jmv.25054

Lõhmus, M., Janse, I., van de Goot, F., and van Rotterdam, B. J. (2013). Rodents as potential couriers for bioterrorism agents. Biosecur. Bioterror. 11, S247-S257.

Lonner, B. N., Douglass, R. J., Kuenzi, A. J., and Hughes, K. (2008). Seroprevalence against Sin Nombre virus in resident and dispersing deer mice. Vector Borne Zoonotic Dis. 8, 433-441. doi: 10.7589/0090-3558-46.2.433

Lundkvist, A., Cheng, Y., Sjölander, K. B., Niklasson, B., Vaheri, A., and Plyusnin, A. (1997). Cell culture adaptation of Puumala hantavirus changes the infectivity for its natural reservoir, Clethrionomys glareolus, and leads to accumulation of mutants with altered genomic RNA S segment. J. Virol. 71, 9515-9523. doi: 10.1128/jvi.71.12.9515-9523.1997

Mackow, E. R., Dalrymple, N. A., Cimica, V., Matthys, V., Gorbunova, E., and Gavrilovskaya, I. (2014). Hantavirus interferon regulation and virulence determinants. Virus Res. 187, 65-71. doi: 10.1016/j.virusres.2013.12.041

Mari Saez, A., Camara, A., Kourouma, F., Sage, M., Magassouba, N., and Fichet-Calvet, E. (2018). Rodent control to fight Lassa fever: evaluation and lessons learned from a 4-year study in Upper Guinea. PLoS Negl. Trop. Dis. 12:e0006829. doi: 10.1371/journal.pntd.0006829

Mariën, J., Borremans, B., Kourouma, F., Baforday, J., Rieger, T., Günther, S., et al. (2019). Evaluation of rodent control to fight Lassa fever based on field data and mathematical modelling. Emerg. Microbes Infect. 8, 640-649. doi: $10.1080 / 22221751.2019 .1605846$

Markotic, A., LeDuc, J. W., Hlaca, D., Rabatic, S., Sarcevic, A., Dasic, G., et al. (1996). Hantaviruses are likely threat to NATO forces in Bosnia and Herzegovina and Croatia. Nat. Med. 2, 269-270. doi: 10.1038/nm0396-269
Martin, T. L., Balser, S. R., Young, G. S., and Lewis, S. D. (2016). Cost and Effectiveness of commercially available nesting substrates for deer mice (Peromyscus maniculatus). J. Am. Assoc. Lab. Anim. Sci. 55, 412-418.

Martinez, V. P., Bellomo, C., San Juan, J., Pinna, D., Forlenza, R., Elder, M., et al. (2005). Person-to-person transmission of Andes virus. Emerg. Infect. Dis. 11, 1848-1853. doi: 10.3201/eid1112.050501

Martinez-Valdebenito, C., Calvo, M., Vial, C., Mansilla, R., Marco, C., Palma, R. E., et al. (2014). Person-to-person household and nosocomial transmission of andes hantavirus, Southern Chile, 2011. Emerg. Infect. Dis. 20, $1629-1636$.

Matheus, S., Kallel, H., Mayence, C., Bremand, L., Houcke, S., and Rousset, D. (2017). Hantavirus pulmonary syndrome caused by Maripa Virus in French Guiana, 2008-2016. Emerg. Infect. Dis. 23, 1722-1725. doi: 10.3201/eid2310. 170842

Matthys, V., and Mackow, E. R. (2012). Hantavirus regulation of type I interferon responses. Adv. Virol. 2012:524024.

McKee, K. T. Jr., Huggins, J. W., Trahan, C. J., and Mahlandt, B. G. (1988). Ribavirin prophylaxis and therapy for experimental argentine hemorrhagic fever. Antimicrob. Agents Chemother. 32, 1304-1309. doi: 10.1128/aac.32.9. 1304

McNab, F., Mayer-Barber, K., Sher, A., Wack, A., and O'Garra, A. (2015). Type I interferons in infectious disease. Nat. Rev. Immunol. 15, 87-103. doi: 10.1038/ nri3787

Medina, R. A., Mirowsky-Garcia, K., Hutt, J., and Hjelle, B. (2007). Ribavirin, human convalescent plasma and anti-beta3 integrin antibody inhibit infection by Sin Nombre virus in the deer mouse model. J. Gen. Virol. 88(Pt 2), 493-505. doi: 10.1099/vir.0.82459-0

Medina, R. A., Torres-Perez, F., Galeno, H., Navarrete, M., Vial, P. A., Palma, R. E., et al. (2009). Ecology, genetic diversity, and phylogeographic structure of andes virus in humans and rodents in Chile. J. Virol. 83, 2446-2459. doi: 10.1128/jvi.01057-08

Meerburg, B. G., Brom, F. W., and Kijlstra, A. (2008). The ethics of rodent control. Pest. Manag. Sci. 64, 1205-1211.

Mertz, G. J., Miedzinski, L., Goade, D., Pavia, A. T., Hjelle, B., Hansbarger, C. O., et al. (2004). Placebo-controlled, double-blind trial of intravenous ribavirin for the treatment of hantavirus cardiopulmonary syndrome in North America. Clin. Infect. Dis. 39, 1307-1313. doi: 10.1086/425007

Meyer, R. F., and Morse, S. A. (2008). "Viruses and Bioterrorism," in Encyclopedia of Virology, Third Edn, eds B.W. J. Mahy and M. H. V. Van Regenmortel (Oxford: Academic Press), 406-411. doi: 10.1016/b978-012374410-4.00549-5

Mir, M. A. (2010). Hantaviruses. Clin. Lab. Med 30, 67-91.

Mir, M. A., Brown, B., Hjelle, B., Duran, W. A., and Panganiban, A. T. (2006). Hantavirus $\mathrm{N}$ protein exhibits genus-specific recognition of the viral RNA panhandle. J. Virol. 80, 11283-11292. doi: 10.1128/jvi.00820-06

Mir, M. A., and Panganiban, A. T. (2004). Trimeric hantavirus nucleocapsid protein binds specifically to the viral RNA panhandle. J. Virol. 78, 8281-8288. doi: 10.1128/jvi.78.15.8281-8288.2004

Mir, M. A., and Panganiban, A. T. (2005). The hantavirus nucleocapsid protein recognizes specific features of the viral RNA panhandle and is altered in conformation upon RNA binding. J. Virol. 79, 1824-1835. doi: 10.1128/jvi.79. 3.1824- 1835.2005

Mir, M. A., and Panganiban, A. T. (2006a). Characterization of the RNA chaperone activity of hantavirus nucleocapsid protein. J. Virol. 80, 6276-6285. doi: 10. 1128/jvi.00147-06

Mir, M. A., and Panganiban, A. T. (2006b). The Bunyavirus nucleocapsid protein is an RNA chaperone: possible roles in viral RNA panhandle formation and genome replication. RNA 12, 272-282. doi: 10.1261/rna.2101906

Mir, M. A., Sheema, S., Haseeb, A., and Haque, A. (2010). Hantavirus nucleocapsid protein has distinct $\mathrm{m} 7 \mathrm{G}$ cap- and RNA-binding sites. J. Biol. Chem. 285, 11357-11368. doi: 10.1074/jbc.m110.102459

Miroslav, P. (2020). Bacillus anthracis as a biological warfare agent: infection, diagnosis and countermeasures. Bratisl. Lek. Listy 121, 175-181. doi: 10.4149/ bll_2020_026

Mittler, E., Dieterle, M. E., Kleinfelter, L. M., Slough, M. M., Chandran, K., and Jangra, R. K. (2019). Hantavirus entry: perspectives and recent advances. Adv. Virus Res. 104, 185-224. doi: 10.1016/bs.aivir.2019.07.002 
Montoya-Ruiz, C., Diaz, F. J., and Rodas, J. D. (2014). Recent evidence of hantavirus circulation in the American tropic. Viruses 6, 1274-1293. doi: 10. 3390/v6031274

Munshi-South, J., and Richardson, J. L. (2017). Peromyscus transcriptomics: Understanding adaptation and gene expression plasticity within and between species of deer mice. Semin. Cell Dev. Biol. 61, 131-139. doi: 10.1016/j.semcdb. 2016.08.011

Muranyi, W., Kehm, R., Bahr, U., Muller, S., Handermann, M., Darai, G., et al. (2004). Bovine aortic endothelial cells are susceptible to hantavirus infection; a new aspect in hantavirus ecology. Virology 318, 112-122. doi: 10.1016/j.virol. 2003.09.006

Muyangwa, M., Martynova, E. V., Khaiboullina, S. F., Morzunov, S. P., and Rizvanov, A. A. (2015). Hantaviral proteins: structure, functions, and role in Hantavirus infection. Front. Microbiol. 6:1326. doi: 10.3389/fmicb.2015.01326

Netski, D., Thran, B. H., and St. Jeor, S. C. (1999). Sin Nombre Virus Pathogenesis in Peromyscus maniculatus. J. Virol. 73, 585-591. doi: 10.1128/jvi.73.1.585-591. 1999

NIAID (2018). US NIAID Emerging Infectious Diseases/ Pathogens. Available online at: https://www.niaid.nih.gov/research/emerging-infectious-diseasespathogens (accessed March 30, 2020).

Nichol, S. T., Spiropoulou, C. F., Morzunov, S., Rollin, P. E., Ksiazek, T. G., Feldmann, H., et al. (1993). Genetic identification of a hantavirus associated with an outbreak of acute respiratory illness. Science 262, 914-917. doi: 10. $1126 /$ science. 8235615

Nicola, M., Alsafi, Z., Sohrabi, C., Kerwan, A., Iosifidis, C., Agha, M., et al. (2020). The socio-economic implications of the Coronavirus and COVID-19 pandemic: a review. Int. J. Surg. 78, 185-193.

Niskanen, S., Jaaskelainen, A., Vapalahti, O., and Sironen, Y. (2019). Evaluation of Real-Time RT-PCR for Diagnostic Use in Detection of Puumala Virus. Viruses 11:661. doi: 10.3390/v11070661

Ophinni, Y., Inoue, M., Kotaki, T., and Kameoka, M. (2018). CRISPR/Cas9 system targeting regulatory genes of HIV-1 inhibits viral replication in infected T-cell cultures. Sci. Rep. 8:7784.

Padula, P., Figueroa, R., Navarrete, M., Pizarro, E., Cadiz, R., Bellomo, C., et al. (2004). Transmission study of Andes Hantavirus infection in wild sigmodontine rodents. J. Virol. 78, 11972-11979. doi: 10.1128/jvi.78.21.11972-11979. 2004

Pan, W., Bian, G., Wang, K., Feng, T., and Dai, J. (2015). Effects of different doses of nucleocapsid protein from Hantaan Virus A9 strain on regulation of interferon signaling. Viral Immunol. 28, 448-454. doi: 10.1089/vim.2015.0004

Park, S. E. (2020). Epidemiology, virology, and clinical features of severe acute respiratory syndrome -coronavirus-2 (SARS-CoV-2, Coronavirus Disease-19). Clin. Exp. Pediatr. 63, 119-124. doi: 10.3345/cep.2020.00493

Parkes, L. O., Nguyen, T. T., Longtin, J., Beaudoin, M. C., Bestman-Smith, J., Vinh, D. C., et al. (2016). A cluster of three cases of hantavirus pulmonary syndrome among canadian military personnel. Can. J. Infect. Dis. Med. Microbiol. 2016:2757969.

Pastorino, B., de Lamballerie, X., and Charrel, R. (2017). Biosafety and Biosecurity in European containment level 3 laboratories: focus on French recent progress and essential requirements. Front. Public Health 5:121. doi: 10.3389/fpubh.2017. 00121

Pizarro, E., Navarrete, M., Mendez, C., Zaror, L., Mansilla, C., Tapia, M., et al. (2019). Immunocytochemical and ultrastructural evidence supporting that Andes Hantavirus (ANDV) is transmitted person-to-person through the respiratory and/or salivary pathways. Front. Microbiol. 10:2992. doi: 10.3389/ fmicb.2019.02992

Plyusnin, A., Vapalahti, O., and Vaheri, A. (1996). Hantaviruses: genome structure, expression and evolution. J. Gen. Virol. 77(Pt 11), 2677-2687. doi: 10.1099/ 0022-1317-77-11-2677

Prescott, J., Feldmann, H., and Safronetz, D. (2017). Amending Koch's postulates for viral disease: When "growth in pure culture" leads to a loss of virulence. Antiviral Res. 137, 1-5. doi: 10.1016/j.antiviral.2016.11.002

Prescott, J., Hall, P., Acuna-Retamar, M., Ye, C., Wathelet, M. G., Ebihara, H., et al. (2010). New World hantaviruses activate IFNlambda production in type I IFN-deficient vero E6 cells. PLoS One 5:e11159. doi: 10.1371/journal.pone. 0011159
Quetier, F. (2016). The CRISPR-Cas9 technology: closer to the ultimate toolkit for targeted genome editing. Plant Sci. 242, 65-76. doi: 10.1016/j.plantsci.2015.09. 003

Richardson, K. S., Kuenzi, A., Douglass, R. J., Hart, J., and Carver, S. (2013). Human exposure to particulate matter potentially contaminated with sin nombre virus. Ecohealth 10, 159-165. doi: 10.1007/s10393-013-0830-x

Riquelme, R., Rioseco, M. L., Bastidas, L., Trincado, D., Riquelme, M., Loyola, H., et al. (2015). Hantavirus pulmonary syndrome, Southern Chile, 1995-2012. Emerg. Infect. Dis. 21, 562-568.

Risteska-Nejashmikj, V., Ristikj-Stomnaroska, D., Bosevska, G., Papa, A., and Stojkovska, S. (2019). Facing of family doctor with Hantavirus infection. Open Access Maced. J. Med. Sci. 7, 1660-1664. doi: 10.3889/oamjms.2019.468

Rizvanov, A. A., Khaiboullina, S. F., and St Jeor, S. (2004). Development of reassortant viruses between pathogenic Hantavirus strains. Virology 327, 225232. doi: 10.1016/j.virol.2004.07.012

Rodriguez, L. L., Owens, J. H., Peters, C. J., and Nichol, S. T. (1998). Genetic reassortment among viruses causing hantavirus pulmonary syndrome. Virology 242, 99-106. doi: 10.1006/viro.1997.8990

Rovida, F., Percivalle, E., Sarasini, A., Chichino, G., and Baldanti, F. (2013). Imported hantavirus cardiopulmonary syndrome in an Italian traveller returning from Cuba. New Microbiol. 36, 103-105.

Sabino-Santos, G. Jr., Maia, F. G. M., Martins, R. B., Gagliardi, T. B., Souza, W. M., Muylaert, R. L., et al. (2018). Natural infection of Neotropical bats with hantavirus in Brazil. Sci. Rep. 8:9018.

Safronetz, D., Falzarano, D., Scott, D. P., Furuta, Y., Feldmann, H., and Gowen, B. B. (2013). Antiviral efficacy of favipiravir against two prominent etiological agents of hantavirus pulmonary syndrome. Antimicrob. Agents Chemother. 57, 4673-4680. doi: 10.1128/aac.00886-13

Safronetz, D., Haddock, E., Feldmann, F., Ebihara, H., and Feldmann, H. (2011). In vitro and in vivo activity of ribavirin against Andes virus infection. PLoS One 6:e23560. doi: 10.1371/journal.pone.0023560

Safronetz, D., Prescott, J., Feldmann, F., Haddock, E., Rosenke, R., Okumura, A. et al. (2014). Pathophysiology of hantavirus pulmonary syndrome in rhesus macaques. Proc. Natl. Acad. Sci. U.S.A. 111, 7114-7119. doi: 10.1073/pnas. 1401998111

Schmaljohn, C. (2009). Vaccines for Hantaviruses. Vaccine 27(Suppl. 4), D61-D64. Schmaljohn, C., and Hjelle, B. (1997). Hantaviruses: a global disease problem. Emerg. Infect. Dis. 3, 95-104. doi: 10.3201/eid0302.970202

Schmaljohn, C. S., Hasty, S. E., and Dalrymple, J. M. (1992). Preparation of candidate vaccinia-vectored vaccines for haemorrhagic fever with renal syndrome. Vaccine 10, 10-13. doi: 10.1016/0264-410x(92)90412-d

Schmaljohn, C. S., Spik, K. W., and Hooper, J. W. (2014). DNA vaccines for HFRS: laboratory and clinical studies. Virus Res. 187, 91-96. doi: 10.1016/j.virusres. 2013.12.020

Sen, G. C., and Sarkar, S. N. (2005). Transcriptional signaling by double-stranded RNA: role of TLR3. Cytokine Growth Factor Rev. 16, 1-14. doi: 10.1016/j. cytogfr.2005.01.006

Seto, T., Tkachenko, E. A., Morozov, V. G., Tanikawa, Y., Kolominov, S. I., Belov, S. N., et al. (2011). An efficient in vivo method for the isolation of Puumala virus in Syrian hamsters and the characterization of the isolates from Russia. J. Virol. Methods 173, 17-23. doi: 10.1016/j.jviromet.2010.12.019

Song, J. Y., Woo, H. J., Cheong, H. J., Noh, J. Y., Baek, L. J., and Kim, W. J. (2016). Long-term immunogenicity and safety of inactivated Hantaan virus vaccine (Hantavax) in healthy adults. Vaccine 34, 1289-1295. doi: 10.1016/j.vaccine. 2016.01.031

Spiropoulou, C. F., Morzunov, S., Feldmann, H., Sanchez, A., Peters, C. J., and Nichol, S. T. (1994). Genome structure and variability of a virus causing hantavirus pulmonary syndrome. Virology 200, 715-723. doi: 10.1006/viro. 1994.1235

Taylor, S. L., Frias-Staheli, N., García-Sastre, A., and Schmaljohn, C. S. (2009). Hantaan virus nucleocapsid protein binds to importin alpha proteins and inhibits tumor necrosis factor alpha-induced activation of nuclear factor kappa B. J. Virol. 83, 1271-1279. doi: 10.1128/jvi.00986-08

Thao, T. T. N., Labroussaa, F., Ebert, N., V’kovski, P., Stalder, H., Portmann, J., et al. (2020). Rapid reconstruction of SARS-CoV-2 using a synthetic genomics platform. Nature 582, 561-565. 
Tian, D., and Zheng, T. (2014). Comparison and analysis of biological agent category lists based on biosafety and biodefense. PLoS One 9:e101163. doi: 10.1371/journal.pone.0101163

Toro, J., Vega, J. D., Khan, A. S., Mills, J. N., Padula, P., Terry, W., et al. (1998). An outbreak of Hantavirus pulmonary syndrome, Chile, 1997. Emerg. Infect. Dis. 4, 687-694.

Vaheri, A., Henttonen, H., Voutilainen, L., Mustonen, J., Sironen, T., and Vapalahti, O. (2013). Hantavirus infections in Europe and their impact on public health. Rev. Med. Virol. 23, 35-49. doi: 10.1002/rmv.1722

Vaheri, A., Vapalahti, O., and Plyusnin, A. (2008). How to diagnose Hantavirus infections and detect them in rodents and insectivores. Rev. Med. Virol. 18, 277-288. doi: $10.1002 / \mathrm{rmv} .581$

Van Loock, F., Thomas, I., Clement, J., Ghoos, S., and Colson, P. (1999). A case-control study after a hantavirus infection outbreak in the south of Belgium: Who is at risk? Clin. Infect. Dis. 28, 834-839. doi: 10.1086/51 5196

Vapalahti, K., Paunio, M., Brummer-Korvenkontio, M., Vaheri, A., and Vapalahti, O. (1999). Puumala virus infections in Finland: increased occupational risk for farmers. Am. J. Epidemiol. 149, 1142-1151. doi: 10.1093/oxfordjournals.aje. a009769

Vapalahti, O., Mustonen, J., Lundkvist, A., Henttonen, H., Plyusnin, A., and Vaheri, A. (2003). Hantavirus infections in Europe. Lancet Infect. Dis. 3, 653-661.

Vergote, V., Laenen, L., Vanmechelen, B., Van Ranst, M., Verbeken, E., Hooper, J. W., et al. (2017). A lethal disease model for New World hantaviruses using immunosuppressed Syrian hamsters. PLoS Negl. Trop. Dis. 11:e0006042. doi: 10.1371/journal.pntd.0006042

Vigueras-Galvan, A. L., Lopez-Perez, A. M., Garcia-Pena, G. E., Rico-Chavez, O., Sarmiento-Silva, R. E., and Suzan, G. (2019). Current situation and perspectives on Hantaviruses in Mexico. Viruses 11:642. doi: 10.3390/v11070642

Waltee, D., Lonner, B. N., Kuenzi, A. J., and Douglass, R. J. (2009). Seasonal dispersal patterns of sylvan deer mice (Peromyscus maniculatus) within Montana rangelands. J. Wildl. Dis. 45, 998-1007. doi: 10.7589/0090-3558-45.4. 998

Wang, X., Shen, W., Qin, Y., Ying, L., Li, H., Lu, J., et al. (2020). A case-control study on the risk factors for hemorrhagic fever with renal syndrome. BMC Infect. Dis. 20:103. doi: 10.1186/s12879-020-4830-5

Warner, B. M., Stein, D. R., Griffin, B. D., Tierney, K., Leung, A., Sloan, A., et al. (2019a). Development and Characterization of a Sin Nombre Virus Transmission Model in Peromyscus maniculatus. Viruses 11:183.

Warner, B. M., Stein, D. R., Jangra, R. K., Slough, M. M., Sroga, P., Sloan, A., et al. (2019b). Vesicular stomatitis virus-based vaccines provide cross-protection against Andes and Sin Nombre Viruses. Viruses 11:645.
Watson, D. C., Sargianou, M., Papa, A., Chra, P., Starakis, I., and Panos, G. (2014). Epidemiology of Hantavirus infections in humans: a comprehensive, global overview. Crit. Rev. Microbiol. 40, 261-272.

Wheelis, M., Casagrande, R., and Madden, L. (2009). Biological attack on agriculture: low-tech, high-impact bioterrorism. Bioscience 52, 569-576.

White, S. M. (2002). Chemical and biological weapons. Implications for anaesthesia and intensive care. Br. J. Anaesth. 89, 306-324.

Williams, M., and Sizemore, D. C. (2020). Biologic, Chemical, and Radiation Terrorism Review. Treasure Island, FL: StatPearls Publishing LLC.

Witkowski, P. T., Perley, C. C., Brocato, R. L., Hooper, J. W., Jurgensen, C., Schulzke, J. D., et al. (2017). Gastrointestinal tract as entry route for Hantavirus infection. Front. Microbiol. 8:1721. doi: 10.3389/fmicb.2017.01721

Woolhouse, M. E., Brierley, L., McCaffery, C., and Lycett, S. (2016). Assessing the Epidemic Potential of RNA and DNA Viruses. Emerg. Infect. Dis. 22, 2037-2044.

Yanagihara, R., Amyx, H. L., and Gajdusek, D. C. (1985). Experimental infection with Puumala virus, the etiologic agent of nephropathia epidemica, in bank voles (Clethrionomys glareolus). J. Virol. 55, 34-38.

Yi, Y., Park, H., and Jung, J. (2018). Effectiveness of inactivated Hantavirus vaccine on the disease severity of hemorrhagic fever with renal syndrome. Kidney Res. Clin. Pract. 37, 366-372.

Ying, Q., Ma, T., Cheng, L., Zhang, X., Truax, A. D., Ma, R., et al. (2016). Construction and immunological characterization of CD40L or GM-CSF incorporated Hantaan virus like particle. Oncotarget 7, 63488-63503.

Zaki, S. R., Greer, P. W., Coffield, L. M., Goldsmith, C. S., Nolte, K. B., Foucar, K., et al. (1995). Hantavirus pulmonary syndrome. Pathogenesis of an emerging infectious disease. Am. J. Pathol. 146, 552-579.

Zhang, Y. Z., Zou, Y., Fu, Z. F., and Plyusnin, A. (2010). Hantavirus infections in humans and animals, China. Emerg. Infect. Dis. 16, 1195-1203.

Zhao, J., Azad, M. B., Bertrand, E. M., Burton, C., Crooks, V. A., Dawson, J., et al. (2020). Canadian Science Meets Parliament: building relationships between scientists and policymakers. Sci. Public Policy 47, 298-298.

Conflict of Interest: The authors declare that the research was conducted in the absence of any commercial or financial relationships that could be construed as a potential conflict of interest.

Copyright (c) 2020 D'Souza and Patel. This is an open-access article distributed under the terms of the Creative Commons Attribution License (CC BY). The use, distribution or reproduction in other forums is permitted, provided the original author(s) and the copyright owner(s) are credited and that the original publication in this journal is cited, in accordance with accepted academic practice. No use, distribution or reproduction is permitted which does not comply with these terms. 